\title{
Sox2 expression in Schwann cells inhibits myelination in vivo and induces influx of macrophages to the nerve
}

\author{
Sheridan L. Roberts ${ }^{1, *}$, Xin-peng Dun ${ }^{1, *}$, Robin D. S. Doddrell ${ }^{1}$, Thomas Mindos ${ }^{1}$, Louisa K. Drake ${ }^{2}$, \\ Mark W. Onaitis ${ }^{3}$, Francesca Florio ${ }^{4}$, Angelo Quattrini ${ }^{5}$, Alison C. Lloyd ${ }^{6}$, Maurizio D'Antonio ${ }^{4}$ \\ and David B. Parkinson ${ }^{1, \pm}$
}

\begin{abstract}
Correct myelination is crucial for the function of the peripheral nervous system. Both positive and negative regulators within the axon and Schwann cell function to ensure the correct onset and progression of myelination during both development and following peripheral nerve injury and repair. The Sox2 transcription factor is well known for its roles in the development and maintenance of progenitor and stem cell populations, but has also been proposed in vitro as a negative regulator of myelination in Schwann cells. We wished to test fully whether Sox2 regulates myelination in vivo and show here that, in mice, sustained Sox2 expression in vivo blocks myelination in the peripheral nerves and maintains Schwann cells in a proliferative non-differentiated state, which is also associated with increased inflammation within the nerve. The plasticity of Schwann cells allows them to re-myelinate regenerated axons following injury and we show that re-myelination is also blocked by Sox2 expression in Schwann cells. These findings identify Sox2 as a physiological regulator of Schwann cell myelination in vivo and its potential to play a role in disorders of myelination in the peripheral nervous system.
\end{abstract}

KEY WORDS: Schwann cell, Myelination, Sox2, Repair, Peripheral nervous system, Mouse

\section{INTRODUCTION}

Schwann cells (SC) are the myelinating glia of the peripheral nervous system (PNS); they myelinate large diameter axons and provide trophic support for both motor and sensory axons. The transcriptional programmes driving both myelination and the dedifferentiation of SCs following injury have been partially characterised and many positive regulators, such as Krox20 (Egr2), Oct6 (SCIP or Tst1), Sox10 and Nfatc4, have been identified by both in vitro and in vivo analysis. However, there is still little data on the potential negative regulators of myelination in vivo that play roles in both the correctly timed onset of myelination and possibly in the pathology of demyelinating neuropathies of the PNS (Topilko et al., 1994;

${ }^{1}$ Plymouth University Peninsula Schools of Medicine and Dentistry, John Bull Building, Plymouth Science Park, Plymouth PL6 8BU, UK. ${ }^{2}$ University of Bath, Bath BA2 7AY, UK. ${ }^{3}$ Department of Thoracic Surgery, University of California, San Diego, CA 92103, USA. "Division of Genetics and Cell Biology, San Raffaele Scientific Institute, DIBIT, 20132 Milan, Italy. ${ }^{5}$ Division of Neuroscience, San Raffaele Scientific Institute, DIBIT, 20132 Milan, Italy. ${ }^{6}$ MRC Laboratory for Molecular Cell Biology, University College London, London WC1E 6BT, UK.

*These authors contributed equally to this work

‡Author for correspondence (david.parkinson@plymouth.ac.uk)

(D) X.P.D., 0000-0003-2837-4672; R.D.S.D., 0000-0002-9509-3910; T.M., 00000003-0870-0696; L.K.D., 0000-0003-2719-2228; D.B.P., 0000-0002-5704-4923

Received 24 February 2017; Accepted 13 July 2017
Svaren and Meijer, 2008; Jaegle et al., 1996; Finzsch et al., 2010; Kao et al., 2009; Jessen and Mirsky, 2008).

Although the transcription factors Pax3, Jun (cJun) and Sox2, activation of the Notch pathway, and signalling through Erk1/2 and p38 mitogen activated protein (MAP) kinases have been shown to inhibit myelination of SCs in vitro, there is only direct genetic evidence available for Notch signalling, Erk1/2 and p38 activation regulating these processes in vivo (Yang et al., 2012; Le et al., 2005; Parkinson et al., 2008; Harrisingh et al., 2004; Woodhoo et al., 2009; Doddrell et al., 2012; Jessen and Mirsky, 2008; Napoli et al., 2012; Ishii et al., 2016, 2013; Roberts et al., 2016).

The high mobility group (HMG) domain transcription factor Sox 2 has been shown in vitro, using $\mathrm{SC} /$ dorsal root ganglion (SC/DRG) co-cultures and adenoviral overexpression of Sox2 in SCs, to inhibit the induction of Krox20 and myelination of axons (Le et al., 2005), but a demonstration of the potential inhibitory role of Sox 2 in vivo within the intact peripheral nerve has not yet been provided. In order to test the role of Sox 2 in vivo, we have made use of a conditional Sox2IRESGFP allele ( $\mathrm{Lu}$ et al., 2010), which is activated in a cellspecific manner by crossing with the SC-specific P0-CRE line, and have tested the effects of ongoing Sox 2 expression upon PNS myelination and repair. These experiments show, for the first time, that in vivo Sox 2 will suppress PNS myelination and re-myelination following injury. In addition, persistent Sox 2 expression in the adult nerve is sufficient to induce SC proliferation and an ongoing inflammatory state within the intact peripheral nerve.

\section{RESULTS}

Sox2 blocks Krox20-driven expression of myelin-associated proteins

The analysis of mice with a hypomorphic allele of Krox20/Egr2 $\left(\right.$ Egr2 $\left.^{\mathrm{Lo} / \mathrm{Lo}}\right)$ showed PNS hypomyelination and continued postnatal expression of the Sox 2 transcription factor in SCs (Le et al., 2005). This study also showed that high levels of Sox 2 in SCs blocked the in vitro induction of Krox20 by cAMP and myelination in SC/DRG co-cultures. Previous analysis of inhibitors of myelination, e.g. Jun, have shown that Jun can both inhibit the induction of Krox20 in SCs as well as prevent the ability of exogenously expressed Krox20 to induce myelinating SC markers. In this way, Jun acts as an inhibitor of myelination both upstream and downstream of Krox20 function (Parkinson et al., 2004). While Sox2 has been shown to block Krox20 induction in SCs by cAMP (Le et al., 2005), we tested whether maintained Sox 2 can also inhibit the action of the promyelinating transcription factor Krox20 in inducing myelinating SC markers (Parkinson et al., 2004). In adenoviral co-infection experiments, as expected, Krox20 induced both the expression of myelin protein zero $\left(\mathrm{P}_{0} ; \mathrm{Mpz}\right)$ and the myelinating cell marker periaxin in SCs (Parkinson et al., 2003, 2004). Co-expression of Sox2 with Krox20 in SCs showed that Sox2 strongly antagonised 

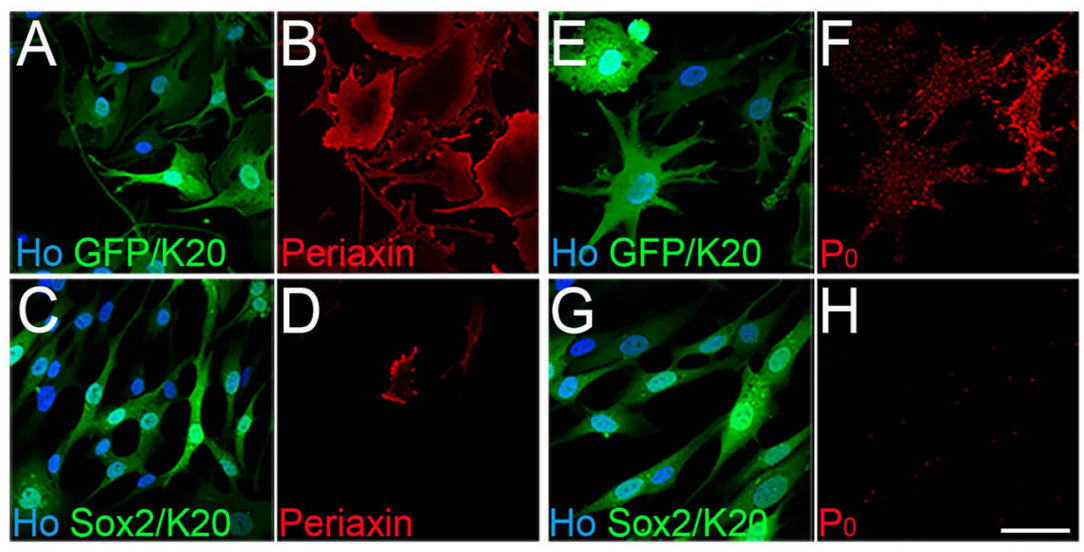

Fig. 1. Sox2 antagonises Krox20-induced myelin protein expression in vitro. (A-H) Immunofluorescence of rat SCs infected with GFP/Krox20- $(A, B, E, F)$ or Sox2/ Krox20- $(C, D, G, H)$ expressing adenovirus, showing inhibition of Krox20-driven periaxin (C,D) and $P_{0}$ expression $(\mathrm{G}, \mathrm{H})$ by Sox2. Hoechst stain $(\mathrm{Ho})$ is used to reveal SC nuclei. Scale bars: $20 \mu \mathrm{m}$. (I) Percentage of periaxin and $\mathrm{P}_{0}$-positive cells in GFP/K20 and Sox2/K20 adenoviral-infected SCs. Two-sided two-sample Student's $t$-test; data from $n=3$ biological replicate experiments; ${ }^{* * *} P<0.005$.

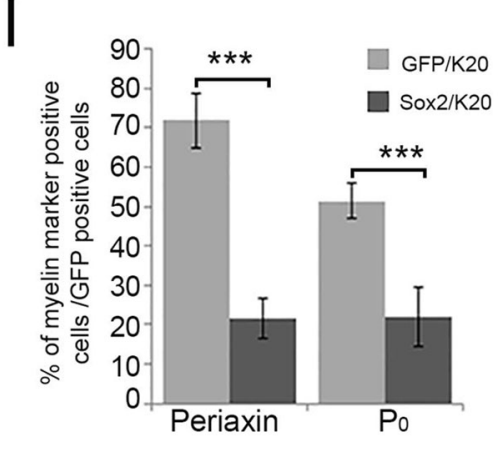

Krox20-induced expression of both $\mathrm{P}_{0}$ and periaxin (Fig. 1A-I), confirming, in vitro, that maintained Sox 2 expression blocks the myelination programme both upstream and downstream of Krox20 induction in SCs.

\section{Sox2 expression inhibits myelination in vivo}

We next tested whether Sox 2 can act as an inhibitor of myelination in vivo within the intact nerve. A conditional overexpressing allele for Sox2 (Sox2IRESGFP), inserted into the Rosa26 locus, has been described that, upon CRE-mediated recombination, expresses both Sox2 and enhanced green fluorescent protein (GFP) (Lu et al., 2010). In order to drive SC-specific expression of Sox2, we used the $\mathrm{mP}_{0}$ TOTA-CRE (P0-CRE) line (Feltri et al., 1999) to remove the floxed 'stop-cassette' sequence and allow cell-specific expression of Sox2 and GFP in SCs. We have characterised nerves from transgenic $\mathrm{CRE}+$ mice that have either one (Sox $\left.2^{\mathrm{HetOE}}\right)$ or both (Sox $2^{\text {HomoOE }}$ ) recombinant Rosa26-Sox2IRESGFP alleles and the effects of Sox 2 expression upon PNS myelination and repair.

We first analysed sciatic nerves of mice carrying one copy of the Sox2IRESGFP transgene. Rosa26 wild-type/Sox2IRESGFP/CRE+ mice (Sox $2^{\mathrm{HetOE}}$ ) showed both Sox 2 and GFP expression in SCs of the nerve. Sox 2 expression in control and Sox $2^{\mathrm{HetOE}}$ nerves was confirmed by western blot and immunolabelling (Fig. 2I,J; Fig. S1A-D). These nerves and controls were analysed at postnatal day (P) 7 and P21 by transmission electron microscopy (TEM) (Fig. 2A-D). Although there is no apparent defect at this stage in axonal sorting (SCs appear to make a normal 1:1 relationship with the axons), there is a substantial reduction in myelin thickness at P7 (Fig. 2B,E) and at P21 (Fig. 2D,G) resulting in an increased average G-ratio $(0.71 \pm 0.003)$ for Sox $2^{\mathrm{HetOE}}$ compared with control $(0.68 \pm$ $0.002)$ at P21. Western blotting of sciatic nerve from control and Sox $2^{\mathrm{HetOE}}$ at both P3 and P7 showed decreased Krox20 as well as reduced myelin proteins $\mathrm{P}_{0}$ and myelin basic protein (MBP, Fig. 2I).
We also observed significant increases in the numbers of unmyelinated axons at both $\mathrm{P} 7$ and $\mathrm{P} 21$ in Sox $2^{\mathrm{HetOE}}$ nerves compared with controls (Fig. 2F,H).

Analysing Sox $2^{\mathrm{HetOE}}$ animals at later timepoints, we observed that the myelination in the PNS appeared to return to normal. At P60 there was no significant difference in G-ratio compared with control animals $\left(0.65 \pm 0.02\right.$ for Sox $2^{\mathrm{HetOE}}$ compared with $0.66 \pm 0.02$ for controls), nerve morphology of Sox $2^{\mathrm{HetOE}}$ nerves was completely normal at P60 (Fig. 3L; Fig. S1J-L) and electrophysiology of Sox $2^{\mathrm{HetOE}}$ nerves showed no changes in nerve conduction velocity at P90 compared with controls (Fig. S1I). We analysed expression of the Sox2IRESGFP transgene in these Sox $2^{\mathrm{HetOE}}$ animals and found that the expression of both Sox 2 and GFP was high at P7 but declined from P21 onwards and was undetectable at later time points, either by western blot or immunocytochemistry; this decrease in GFP expression was associated with onset of myelination in the Sox $2^{\mathrm{HetOE}}$ nerves (Fig. 2J; Fig. S1A-H). We were unable to discern why expression levels of Sox 2 and GFP decline in these Sox $2^{\mathrm{HetOE}}$ mice, but it does show that loss of Sox 2 overexpression in a hypomyelinated nerve from P21 onwards will allow myelination to proceed such that it appears normal by P60 in the mouse PNS.

Next, we performed crosses to generate animals carrying two copies of the Sox2IRESGFP transgene and examined whether in this case Sox 2 expression persisted in the nerve in CRE+ (Sox $2^{\mathrm{HomoOE}}$ ) animals and effects of such expression. Sox $2^{\text {HomoOE }}$ animals showed a similar hypomyelinating phenotype with ongoing Sox 2 expression at P7, P14 and P21 time points in $\mathrm{CRE}+$ animals and Sox 2 continued to be expressed up to $\mathrm{P} 60$, as measured by either immunolabelling or western blot (Fig. 3A-H,K and data not shown).

P60 adult Sox $2^{\mathrm{HomoOE}}$ animals were smaller in size compared with controls and showed a typical hindlimb clasping when lifted by 


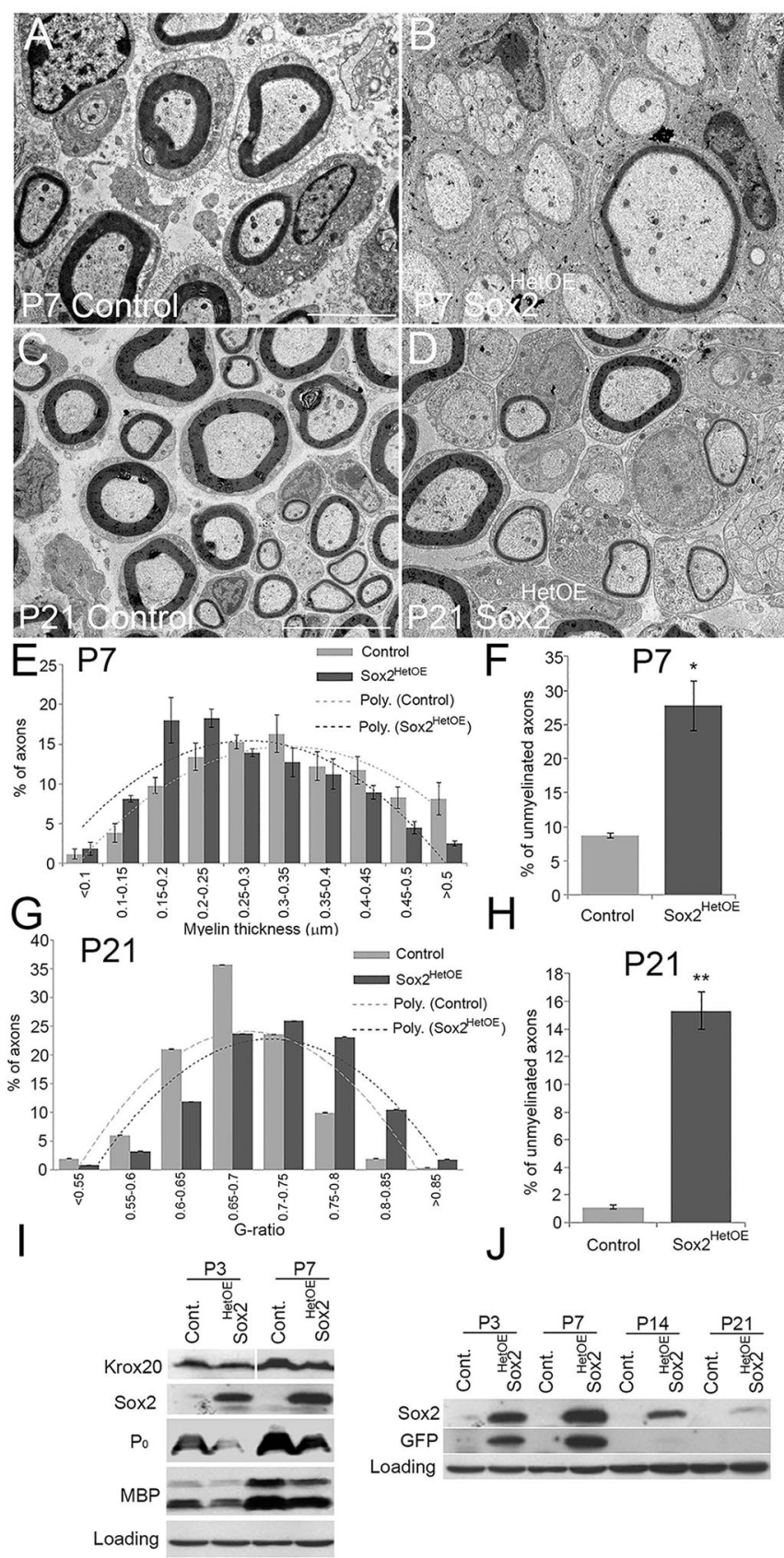

Fig. 2. Inhibition of myelination in Sox2-overexpressing mice in vivo. (A-D) TEM of sciatic nerves from control P7 control (A) and Sox $2^{\mathrm{HetOE}}$ (B) mice, and P21 control (C) and Sox $2^{\text {HetOE }}$ (D) mice. Scale bars: $5 \mu \mathrm{m}$. (E) The distribution of myelin thickness in P7 control and Sox $2^{\text {HetOE }}$ mouse nerves. (F) There is a significant increase in the proportion of unmyelinated axons greater than $1 \mu \mathrm{m}$ in diameter in the sciatic nerves of P7 Sox ${ }^{\mathrm{HetOE}}$ mice compared with controls. (G) The distribution of the G-ratio of axons in P21 control and Sox $2^{\text {HetOE }}$ nerves. $n=3$ mice of each genotype. $(H)$ There is a significant increase in the population of unmyelinated axons greater than $1 \mu \mathrm{m}$ in diameter in nerves of P21 Sox $2^{\mathrm{HetOE}}$ mice compared with control mice. $(\mathrm{F}, \mathrm{H})$ Two-sided two-sample Student's $t$-test; data from $n=3$ mice of each genotype; ${ }^{*} P<0.05,{ }^{* *} P<0.01$. (I) Western blots showing the reduction in Krox20, $\mathrm{P}_{0}$ and myelin basic protein (MBP) proteins in P3 and P7 control and Sox $2^{\text {HetOE }}$ nerves. $(\mathrm{J})$ Western blots showing Sox2 and GFP expression in postnatal control and Sox $2^{\mathrm{HetOE}}$ mice.

the tail (Fig. 3N-P), indicating a possible reduction of PNS myelination. TEM analysis of P60 Sox $2^{\mathrm{HomoOE}}$ nerves showed hypomyelination within the adult nerve (Fig. 3I,J), showing that ongoing Sox 2 expression will inhibit myelination even at this later time point in vivo. Immunocytochemistry and western blotting of Sox $2^{\mathrm{HomoOE}}$ nerves at both $\mathrm{P} 7$ and $\mathrm{P} 60$ showed reduced levels of Krox20 and of the myelin proteins $\mathrm{P}_{0}$ and MBP (Fig. 3K; Fig. S2A$\mathrm{F}, \mathrm{I})$. Levels of the Sox 10 transcription factor protein, a key driver of myelination (Finzsch et al., 2010; Fröb et al., 2012), were unchanged at P7, but actually increased in Sox $2^{\mathrm{HomoOE}}$ nerves at P60 (Fig. S2G), presumably due to increased numbers of SCs within the nerve (see below and Fig. 7). Corresponding to the reduction in myelin protein expression, a significant increase in the G-ratio and numbers of unmyelinated axons was observed in Sox $2^{\mathrm{HomoOE}}$ nerves at P60 compared with control and Sox $2^{\mathrm{HetOE}}$ animals (Fig. 3L,M).

More-detailed examination of P7 and P60 Sox $2^{\mathrm{HomoOE}}$ nerves showed a number of additional effects of Sox2 expression upon nerve morphology. At P7, although SCs are making a 1:1 relationship with axons, there is stalling of the ensheathment (Fig. 4A,B). In addition, at this age, where myelination is observed, we see an apparent lack of compaction in the outer myelin membrane layers of the SCs (Fig. 4D,E). At P60, semi-thin and cryostat sections of Sox $2^{\mathrm{HomoOE}}$ nerves show reduced myelination, but also evidence of both axonal loss and ongoing myelin breakdown (Fig. 4F,G,Q-T). Additionally, at P60 we saw highly disorganised Remak bundles within the Sox $2^{\mathrm{HomoOE}}$ nerves, with groups of small diameter axons not separated by SC cytoplasm, in contrast to control nerves, and observed SCs extending abnormal processes and engulfing collagen fibres (Fig. 4H-L). An examination of basal lamina structure in P60 Sox $2^{\mathrm{HomoOE}}$ nerves with $\alpha 6$ integrin and laminin $\alpha 2$ staining showed an abnormal and diffuse staining pattern in Sox $2^{\mathrm{HomoOE}}$ nerves when compared with controls (Fig. 4M-P). Similar behaviour was observed using in vitro SC/DRG myelinating co-cultures with Sox2-overexpressing SCs; 21 days after ascorbic acid addition to trigger myelination, Sox2overexpressing SCs did not associate correctly with axons, produced many cellular processes and very little myelin when compared with controls (Fig. S3).

\section{Sox2 overexpression reduces nerve conduction velocity (NCV), motor function and sensory function}

Following on from the molecular characterisation of nerves overexpressing Sox2, we next compared the NCV in control and Sox $2^{\text {HetOE }}$ animals. Analysis of compound action potentials revealed that Sox $2^{\mathrm{HetOE}}$ nerves have significantly decreased NCVs compared with control nerves at P21 (Fig. 5A; see Fig. S4C for examples of original electrophysiological recordings), although this had corrected by P90 (Fig. S1I), consistent with the normal myelination at this timepoint in these animals (Fig. S1J-L). Next, motor functional analysis was tested using a rotarod with an increasing speed by recording the latency to fall (Saporta et al., 2012; Wrabetz et al., 2006). A significantly reduced latency was observed in Sox $2^{\mathrm{HomoOE}}$ mice at both 6 weeks and 8 weeks of age. Although not significant, a slight reduction in latency was observed in Sox $2^{\mathrm{HetOE}}$ mice at 6 weeks and 8 weeks of age (Fig. 5B,C).

Further analysis of sensory function was carried out using toe pinch (pressure) and Von Frey filament (light touch) testing. At 6 weeks, toe pinch testing showed a reduction in the ability of Sox $2^{\mathrm{HomoOE}}$ mice to response to pressure stimuli, compared with control and Sox $2^{\mathrm{HetOE}}$ mice (Fig. S4A). In testing using Von Frey filaments, we found that Sox $2^{\mathrm{HomoOE}}$ mice also had a significantly decreased ability to respond to light touch stimuli compared with control mice (Fig. S4B). 


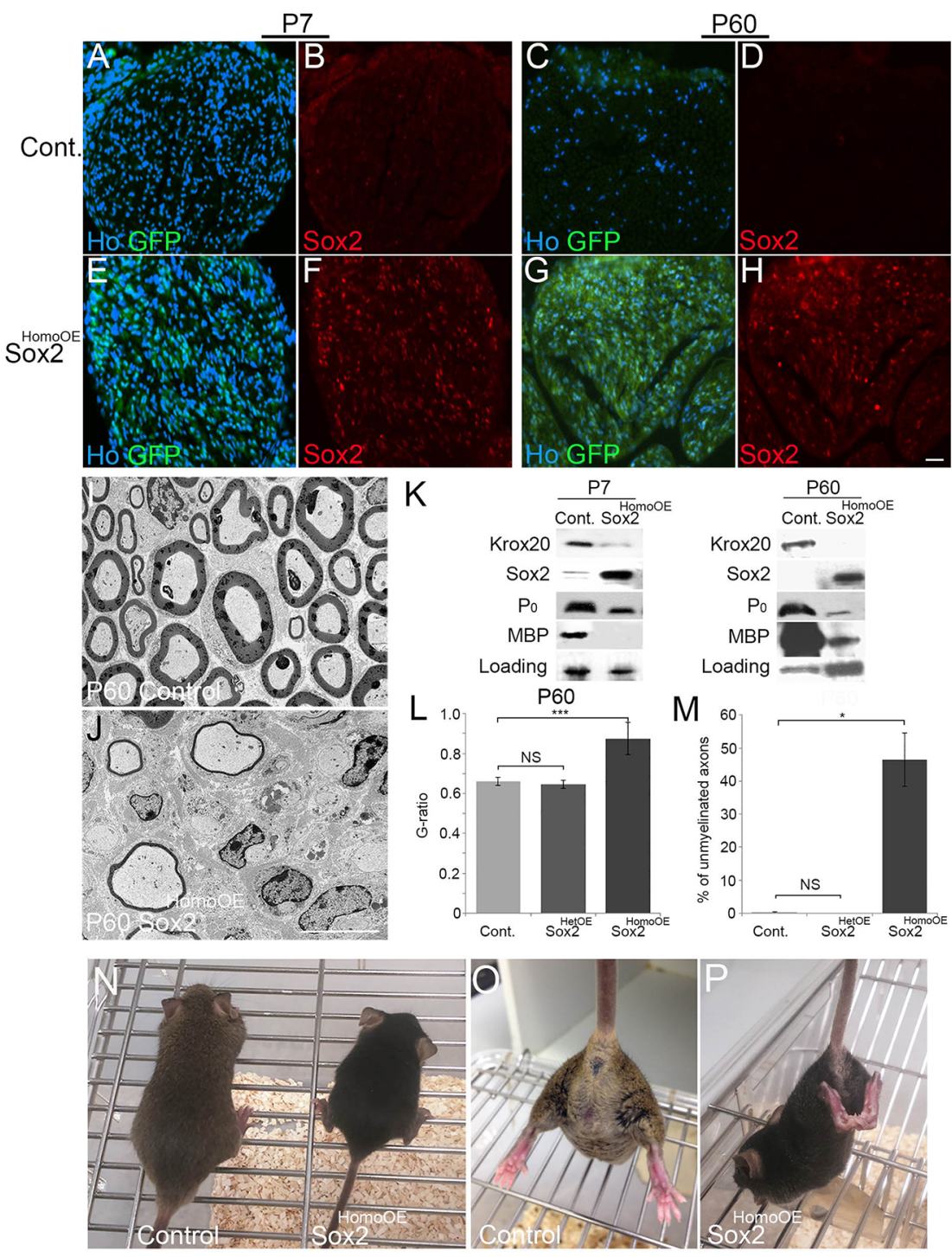

Fig. 3. Analysis of Sox2 expression and myelination in Sox $2^{\text {HomoOE }}$ mice carrying two copies of the

Sox2IRESGFP transgene. (A-H) Immunohistochemical analysis of sciatic nerves demonstrates that control nerves do not express GFP or Sox2 at P7 (A,B) or P60 (C,D), whereas Sox $2^{\text {HomoOE }}$ nerves have high levels of GFP and Sox2 expression at both P7 (E,F) and P60 (G,H). Scale bar: $40 \mu \mathrm{m}$. (I,J) TEM images of control (I) and Sox $2^{\text {HomoOE }}(\mathrm{J})$ nerves at P60. Scale bar: $5 \mu \mathrm{m}$. (K) Western blots of control and Sox $2^{\mathrm{HomoOE}}$ nerves at $\mathrm{P} 7$ and P60 showing reduction in Krox20, $\mathrm{P}_{0}$ and MBP expression in vivo mediated by Sox2 expression in SCs. (L,M) G-ratio measurements (L) and numbers of unmyelinated axons greater than $1 \mu \mathrm{m}$ in diameter $(\mathrm{M})$ in control, Sox $2^{\mathrm{HetOE}}$ and Sox $2^{\mathrm{HomoOE}}$ nerves at P60.

Two-sided two-sample Student's $t$-test; data from $n=3$ mice of each genotype; ${ }^{*} P<0.05,{ }^{* * *} P<0.005$

(N) Sox $2^{\mathrm{HomoOE}}$ mice (black, on right of picture) were smaller at P60 compared with control animals. (O,P) Sox $2^{\text {HomoOE }}$ animals $(P)$ show hind limb clasping when lifted by the tail, which is characteristic of peripheral hypomyelination, when compared with control littermate $(\mathrm{O})$.

\section{Increased levels of immature SC markers $\mathbf{N}$-cadherin and Jun in adult Sox2 ${ }^{\text {HomoOE }}$ nerves}

$\mathrm{N}$-cadherin is expressed in developing nerve and declines during myelination with a reciprocal upregulation of E-cadherin, but is re-expressed following nerve injury (Crawford et al., 2008; Wanner et al., 2006). Expression of Sox 2 in SCs has been shown to drive relocalisation of $\mathrm{N}$-cadherin, a cell-surface adhesion molecule, and allow SC clustering in the nerve bridge following injury (Parrinello et al., 2010). Such clustering is effected by the formation of adherens junctions through a calcium-dependent homophilic cadherin-cadherin interaction between SCs (Wanner and Wood, 2002). Immunolabelling of P60 sciatic nerve sections showed a clear increase in $\mathrm{N}$-cadherin levels in $\mathrm{SCs}$ from Sox $2^{\mathrm{HomoOE}}$ nerves compared with controls with an apparent cell membrane localisation (Fig. 6A-D). Western blotting confirmed an increase in N-cadherin levels in Sox $2^{\mathrm{HomoOE}}$ nerves, as well as increased levels of the Jun transcription factor, a marker of promyelinating SCs (Parkinson et al., 2004) (Fig. 6I,J).

$\beta$-Catenin is an $\mathrm{N}$-cadherin binding partner and has been shown to both colocalise at the SC-axon interface to regulate SC polarity (Lewallen et al., 2011) and to positively regulate SC proliferation in SC-DRG co-cultures (Gess et al., 2008).
$\beta$-Catenin immunolabelling and western blotting showed slightly raised levels of expression in $\mathrm{P} 60$ Sox $2^{\mathrm{HomoOE}}$ nerves in vivo (Fig. 6E-J). Corresponding in vitro experiments with rat SCs showed that enforced Sox2 expression alters SC morphology (Fig. S5A,B), localises both $\mathrm{N}$-cadherin and $\beta$-catenin to the SC membrane in a calcium-dependent manner (Fig. S5C-J), and increased the levels of both proteins (Fig. S5K); interestingly, expression of a 4-hydroxytamoxifen-regulatable Sox2 (Sox2$\mathrm{ER}^{\mathrm{TM}}$ ) protein in $3 \mathrm{~T} 3$ fibroblasts was sufficient to drive upregulation and membrane localisation of the N-Cadherin protein after the addition of tamoxifen to this heterologous cell type (Fig. S6A-E).

\section{SC proliferation is increased by Sox2 expression in vivo}

In Sox $2^{\mathrm{HomoOE}}$ mice, we saw increased numbers of SCs within the nerve from P7 onwards (Fig. 7G,H; Fig. S7). To identify whether Sox 2 increased SC proliferation in vivo, we immunolabelled P7 and P60 nerve sections with Ki67. The number of GFP/Ki67-positive nuclei was significantly increased in Sox $2^{\mathrm{HomoOE}}$ mice at both P7 and P60 (Fig. 7A-F,I,J); however, no significant increase in Ki67 staining or nuclei number was detected at time points as early as P3 (Fig. S7A-E; data not shown). 


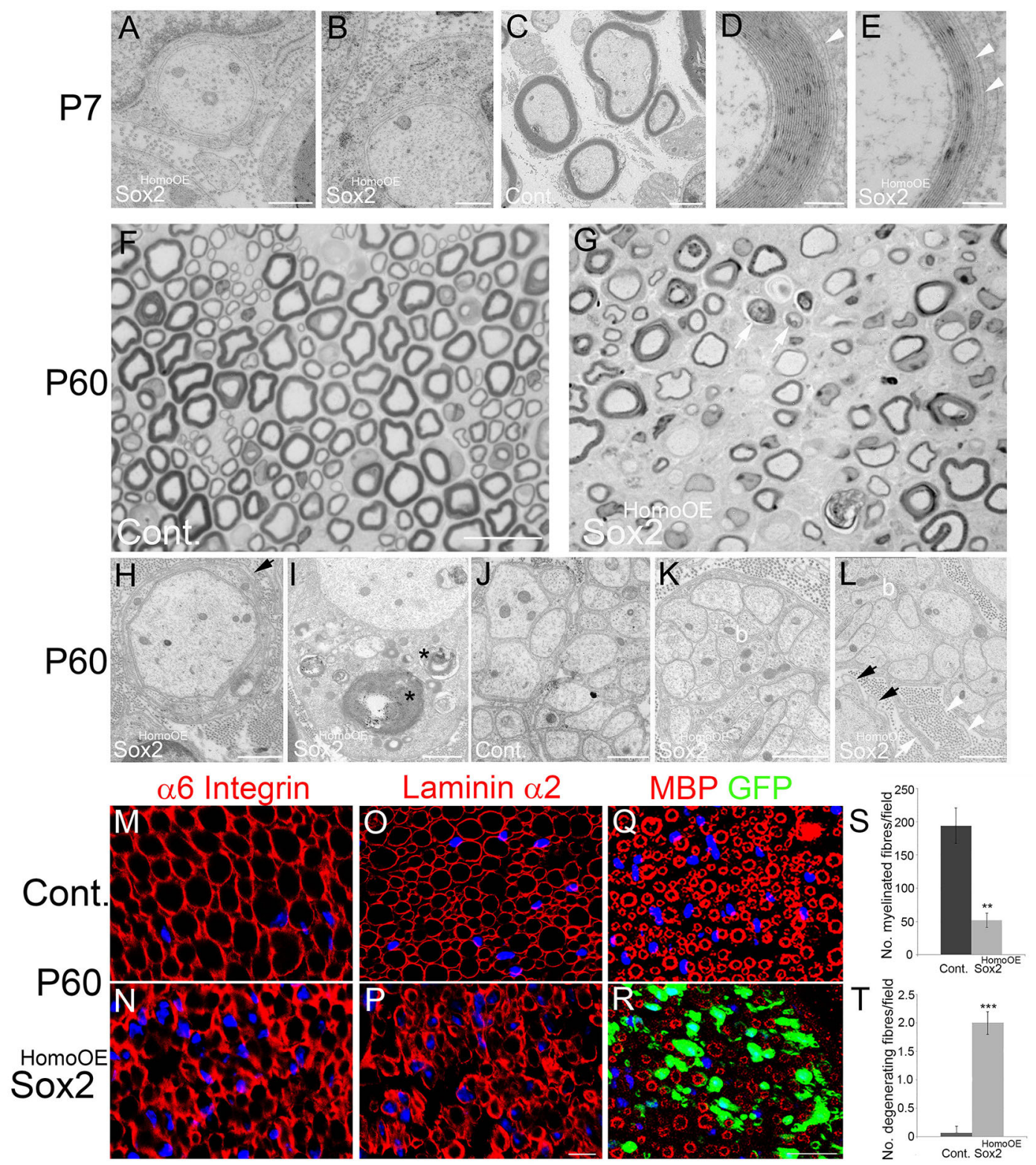

Fig. 4. Morphology of $P 7$ and $P 60$ control and Sox $2^{\text {HomoOE }}$ nerves. (A-E) P7 sciatic nerves from control (C) and Sox $2^{\text {HomoOE }}$ animals $(A, B, D, E)$. Whereas control nerve SCs have formed proper myelin (C), in Sox ${ }^{\text {HomoOE }}$ nerves most SCs are stalled in the 1:1 stage (A,B). (D,E) Where Sox2-overexpressing SCs do form myelin, they often show non-compaction of outer myelin layers (white arrowheads). Scale bars: $500 \mathrm{~nm}$ in A,B; $2 \mu \mathrm{m}$ in C; $200 \mathrm{~nm}$ in D,E. (F,G) Semi-thin sections of P60 control (F) and Sox $2^{\text {HomoOE }}(\mathrm{G})$ nerves; arrows in $\mathrm{G}$ indicate possible axonal loss and demyelination. Scale bar: $20 \mu \mathrm{m}$. (H-L) P60 control (J) and Sox2 ${ }^{\mathrm{HomoOE}}(\mathrm{H}, \mathrm{I}, \mathrm{K}, \mathrm{L})$ nerves. At P60, most axons in Sox2 ${ }^{\mathrm{HomoOE}}$ nerves are amyelinated and surrounded by redundant $\mathrm{SC}$ basal lamina (black arrows in $\mathrm{H}$ and $\mathrm{L}$ ), and several SCs show myelin debris in the cytoplasm (asterisks in I). Remak bundles, which in control nerves show proper SC cytoplasm separating axons (J), show bundles of axons touching each other (' $b$ ' in $K$ and $L$ ) and aberrant SC processes (white arrow in $L$ ), the basal lamina of which forms collagen pockets (white arrowheads in L). Scale bars: $1 \mu \mathrm{m}$ in H-L. (M-R) P60 control (M,O,Q) and Sox2 $2^{\text {HomoOE }}(\mathrm{N}, \mathrm{P}, \mathrm{R})$ nerve sections immunolabelled with $\alpha 6$ integrin $(\mathrm{M}, \mathrm{N})$, laminin $\alpha 2(\mathrm{O}, \mathrm{P})$ and myelin basic protein (MBP)/GFP (Q,R). Scale bars: $5 \mu \mathrm{m}$ in M-P; $25 \mu \mathrm{m}$ in Q,R. (S,T) Quantification of myelinated (S) and degenerating (T) fibres per field in P60 control and Sox2 ${ }^{\text {HomoOE }}$ nerves. Two-sided two-sample Student's $t$-test; data from $n=3$ mice of each genotype; ${ }^{* \star} P<0.01,{ }^{* \star \star} P<0.005$.

\section{Increased numbers of macrophages in uninjured Sox2- overexpressing nerves}

Having observed that increased Sox 2 expression maintains SCs in a proliferative non-myelinating state in the adult nerve, and also some myelin breakdown and axonal degeneration, we next tested whether this was associated with any increase in macrophages and other immune cells within the intact nerve. By double labelling for Iba1 and F4/80, we checked macrophage numbers in P7, P21 and P60 control and Sox $2^{\text {HomoOE }}$ nerves, and found a significant increase in the numbers of macrophages within these intact
Sox $2^{\mathrm{HomoOE}}$ nerves at both P21 and P60 (Fig. 8A-G). An increase, although not significant, was also found in numbers of CD3positive T-cells in intact $\mathrm{P} 60 \mathrm{Sox} 2^{\mathrm{HomoOE}}$ nerves compared with controls (Fig. S8).

\section{Sox2 over-expression impairs SC remyelination and functional recovery following nerve injury}

Although Sox 2 re-expression has been shown to drive cell sorting in the nerve bridge following transection injury (Parrinello et al., 2010), it is not known how maintained Sox2 expression in SCs will 

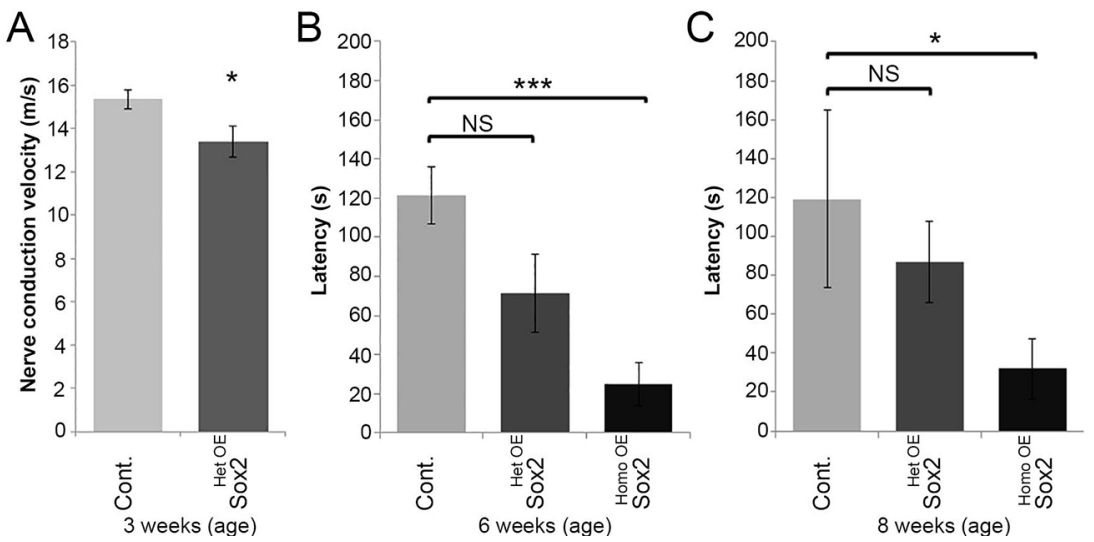

Fig. 5. Nerve conduction velocity and motor function is reduced in Sox2-overexpressing animals. (A) The nerve conduction velocities (NCV) of sciatic nerves taken from control $(n=11)$ and Sox ${ }^{\mathrm{HetOE}}(n=13)$ mice at P21.

$(B, C)$ Reduction in latency to fall using rotarod testing of control, Sox $2^{\mathrm{HetOE}}$ and Sox $2^{\mathrm{HomoOE}}$ mice at 6 weeks $(\mathrm{B})$ and 8 weeks (C) of age. 6 weeks control, $n=7$; Sox $2^{\mathrm{HetOE}}, n=4$; Sox2 ${ }^{\mathrm{HomoOE}}, n=6$; 8 weeks control, $n=4$; Sox $2^{\mathrm{HetOE}}, n=4$; Sox $2^{\text {HomoOE }}, n=6$. Two-sided two-sample Student's $t$-test; ${ }^{*} P<0.05,{ }^{* * *} P<0.005$. affect nerve repair and regeneration in the distal nerve following a crush injury. Thus, we next investigated the effect of maintained Sox2 expression on SC re-myelination up to 21 days post-crush injury (DPI). As Sox $2^{\mathrm{HomoOE}}$ animals show profound hypomyelination even at $\mathrm{P} 60$, we used Sox $2^{\mathrm{HetOE}}$ animals for these experiments. As described above, in Sox $2^{\mathrm{HetOE}}$ mice, Sox 2 and GFP expression begins to decline at P21 and myelination corrects to produce normal nerve morphology and G-ratios at P60; nerve conduction velocity is also unchanged at P90 in these animals (above and Fig. S1I-L).

As we observe transgene expression of both Sox 2 and GFP at early developmental timepoints in the Sox $2^{\mathrm{HetOE}}$ animals, we hypothesized that following PNS injury the accompanying dedifferentiation of SCs distal to the injury site may be sufficient to cause re-activation of transgenic Sox 2 and GFP expression in the Sox $2^{\mathrm{HetOE}}$ animals, allowing us to study effects of ongoing Sox2 expression in a repairing nerve. This idea proved correct and western blot and immunolabelling showed higher levels of Sox2 induction in Sox $2^{\mathrm{HetOE}}$ animals compared with controls at 7 DPI and that Sox 2 and GFP expression were maintained at 21 DPI in these animals compared with controls (Fig. 9A-F,L,M). Using TEM, we evaluated SC re-myelination by analysing distal nerve sections from control and Sox $2^{\mathrm{HetOE}}$ mice at 21 DPI. Sox $2^{\mathrm{HetOE}}$ sciatic nerves distal to the site of injury were hypomyelinated (Fig. 9G,H), with a significantly increased average G-ratio of $0.86 \pm 0.028$ compared with control nerves, which had an average G-ratio of $0.69 \pm 0.028$ at this timepoint (Fig. 9I; see Fig. S9A for G-ratio scatter plot). A significant increase in the percentage of unmyelinated axons and a decrease in $\mathrm{P}_{0}$ protein expression were observed in Sox $2^{\mathrm{HetOE}}$ mouse nerves at $21 \mathrm{DPI}$ (Fig. 9J,M).

Although numbers of regenerated axons were apparently unchanged, as visualised by neurofilament staining, further analysis of regenerated nerves at 21 DPI did show a significant increase in the axonal diameter of repaired nerves in Sox $2^{\mathrm{HetOE}}$ animals compared with controls (Fig. S9B), as well as significantly increased numbers of macrophages still present within the nerve at this timepoint (Fig. S9C-G). No significant difference in macrophage numbers was observed between uninjured nerves from control and Sox $2^{\mathrm{HetOE}}$ animals (Fig. S9G).

Having observed that Sox 2 overexpression post-injury leads to a marked reduction in $\mathrm{SC}$ re-myelination in $\mathrm{Sox} 2{ }^{\mathrm{HetOE}}$ mice following injury, we next tested functional recovery of these animals. Tests of functional recovery using a Static Sciatic Index (SSI) measurement showed that recovery in Sox $2^{\mathrm{HetOE}}$ mice was significantly reduced up to 21 DPI compared with control mice (Fig. 9K). This experiment confirmed that, in addition to impairing remyelination, prolonged Sox 2 expression in SCs following injury also attenuates functional recovery in these animals.

We next quantified re-myelination by analysing myelin protein reexpression following sciatic nerve injury. Corresponding to TEM

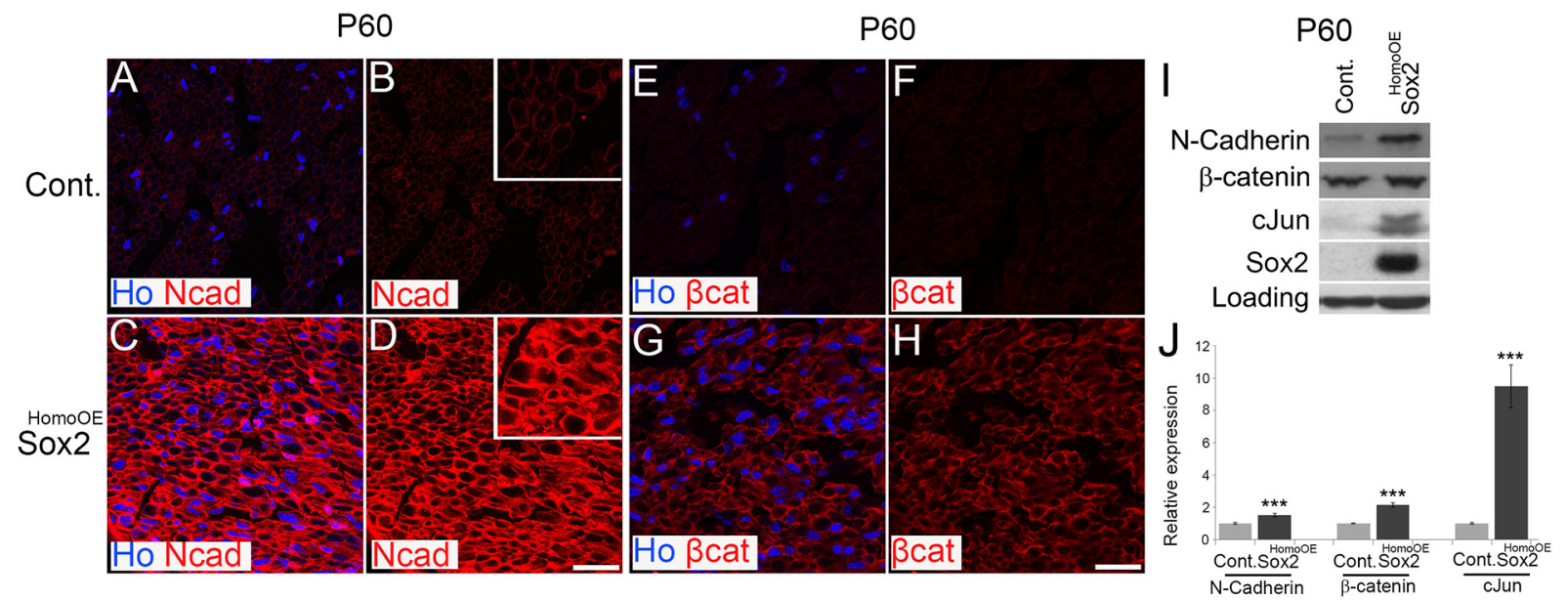

Fig. 6. Expression and localisation of $\mathbf{N}$-cadherin and $\boldsymbol{\beta}$-catenin in $\mathbf{P} 60$ Sox $2^{\mathrm{HomoOE}}$ nerves. (A-H) Immunolabelling of sciatic nerve sections from $\mathrm{P} 60$ control $(A, B, E, F)$ and Sox $2^{\text {HomoOE }}(C, D, G, H)$ nerves showing localisation and levels of N-cadherin (Ncad; A-D) and $\beta-c a t e n i n(\beta c a t ; E-H)$ in SCs. Sections are counterstained with Hoechst $(\mathrm{Ho})$ to reveal nuclei. Scale bar: $20 \mu \mathrm{m}$. (I) Western blot showing elevated levels of Sox2, N-cadherin and Jun in P60 Sox ${ }^{\mathrm{H} o m o O E}$ nerves. (J) Quantification of western blots in I. Two-sided two-sample Student's $t$-test; data from $n=3$ blots; ${ }^{* * *} P<0.005$. 


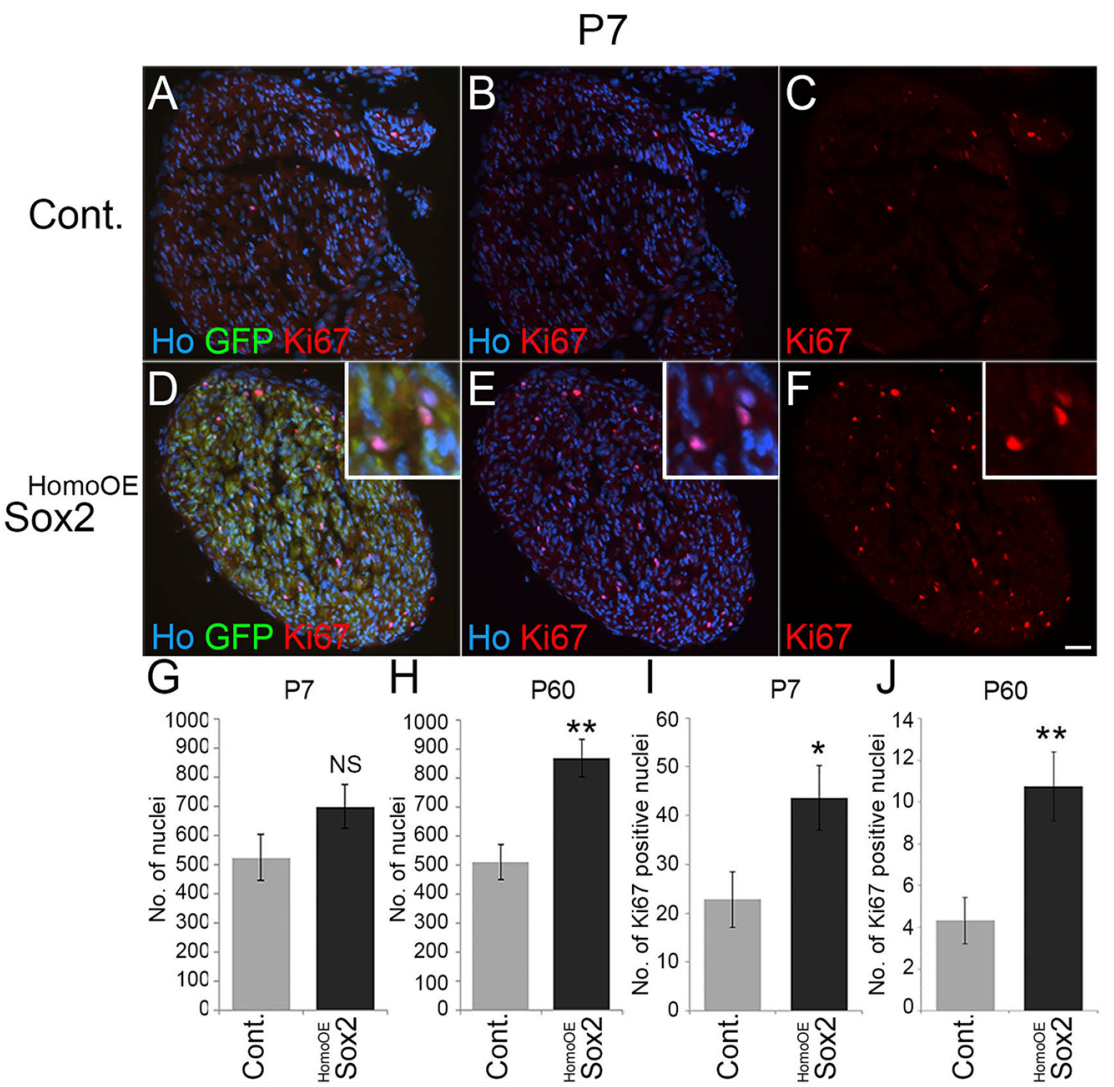

Fig. 7. SC numbers and proliferation are increased in Sox2-overexpressing nerves. (A-F) Ki67 labelling of sciatic nerves taken from $\mathrm{P} 7$ control $(\mathrm{A}-\mathrm{C})$ and Sox2 ${ }^{\text {HomoOE }}$ (D-F) mice. Scale bar: $40 \mu \mathrm{m}$. Insets in D-F show higher magnification of Ki67/GFP-positive SCs. $(\mathrm{G}, \mathrm{H})$ There is an increase in the number of SC nuclei in P7 (G) and P60 (H) Sox2 ${ }^{\text {HomoOE }}$ sciatic nerves compared with controls. Numbers given are total nuclei per sciatic nerve transverse section. $(\mathrm{I}, \mathrm{J})$ There is a significant increase in the number of GFP/Ki67-positive nuclei in P7 (I) and P60 (J) Sox2 ${ }^{\text {HomoOE }}$ sciatic nerves. (G-J) Twosided two-sample Student's $t$-test; data from $n=3$ mice of each genotype at each time point; ${ }^{*} P<0.05,{ }^{* *} P<0.01$. analysis (Fig. 9G,H), western blotting confirmed that continued expression of Sox 2 in the SCs of Sox $2^{\text {HetOE }}$ nerves following injury reduced the re-expression of $\mathrm{P}_{0}$ at 21 DPI in the distal nerve (Fig. 9L,M). Analysis of SC proliferation in Sox $2^{\mathrm{HetOE}}$ mice at $21 \mathrm{DPI}$ also showed an ongoing and significantly increased proliferation in the nerve even at this timepoint after injury (Fig. 9N), once more showing the potential for Sox2 to maintain SCs in an undifferentiated and proliferative state in vivo within the nerve.

\section{DISCUSSION}

Within SCs, the onset of myelination is controlled by a network of transcription factors that cooperate to ensure a timely and appropriate ensheathment and myelination of axons (Svaren and Meijer, 2008). Mutations in many of these factors, such as those in the zinc-finger protein Krox20 (Egr2), cause hypomyelinating neuropathies in both humans and rodent models (Funalot et al., 2012; Baloh et al., 2009; Desmazieres et al., 2008; Arthur-Farraj et al., 2006; Warner et al., 1999, 1998). Although there are a number of positive transcriptional regulators of myelination in SCs, such as Krox20, Sox10, Nfatc4 and Oct6, an increasing number of negative regulators of myelination, such as MAP kinase signalling through $\mathrm{p} 38$ and ERK1/2 pathways, Notch signalling and the transcription factors Pax3 and Jun, have been shown to block the myelination of SCs (Doddrell et al., 2012; Harrisingh et al., 2004; Woodhoo et al., 2009; Napoli et al., 2012; Yang et al., 2012; Parkinson et al., 2004, 2008).

The initial description of Sox 2 as an inhibitor of PNS myelination came from the finding that mice with a hypomorphic Krox20 (Egr2) allele $\left(\mathrm{Egr} 2^{\mathrm{Lo} / \mathrm{Lo}}\right)$, and thus reduced Krox20 expression, showed hypomyelination and increased expression of Sox 2 in SCs. Further experiments, which aimed to determine the function of Sox 2 as a negative regulator of myelination have used a virally mediated expression system in vitro. These experiments showed that overexpression of Sox 2 in vitro prevents both the induction of myelinating SC markers such as Krox 20 and $\mathrm{P}_{0}$, and enhanced the proliferation of SCs to the mitogen neuregulin (Le et al., 2005). Although this gives a good indication of Sox 2 function, assays of myelination in vitro may not fully reflect the situation in vivo (Lewallen et al., 2011; Golan et al., 2013). Thus, the aim of this study was to fully characterise the effects of maintained Sox 2 expression upon both myelination and functional repair within the intact nerves of the PNS in vivo. In addition, this in vivo approach allows us to measure effects of maintained Sox 2 expression in SCs upon immune cell influx into the nerve, both following injury and in the intact nerve.

Our experiments show a strong inhibitory effect of Sox 2 on the myelination programme of SCs at all timepoints examined. The expression of myelinating SC markers such as Krox20, myelin basic protein and $\mathrm{P}_{0}$ are all reduced, and morphological analysis shows a severe hypomyelination of postnatal nerves. Correspondingly, an analysis of SC-specific Sox2 nulls has shown a slight acceleration of early postnatal myelination (M.D. and X.P.D., unpublished), confirming the inhibitory role of Sox 2 in controlling developmental myelination. However, in contrast to experiments with SC-specific Jun and p38 $\alpha$ MAP kinase nulls (Parkinson et al., 2008; Roberts et al., 2016), we do not observe a function for Sox 2 in the downregulation of myelin proteins following injury. Injury experiments in Sox2-null nerves showed a similar profile of myelin protein loss compared with controls (X.P.D., unpublished). Thus, the role of Sox 2 appears to be more important in regulating the onset of myelination both during development and following injury, rather than in the events of SC dedifferentiation following axotomy.

An analysis of other potential Sox 2 targets showed, both in vitro and in vivo, that Sox 2 decreased mRNA and protein levels of the nectinlike protein Necl4 (also known as Cadm4) in SCs (Fig. S10). Inhibition 


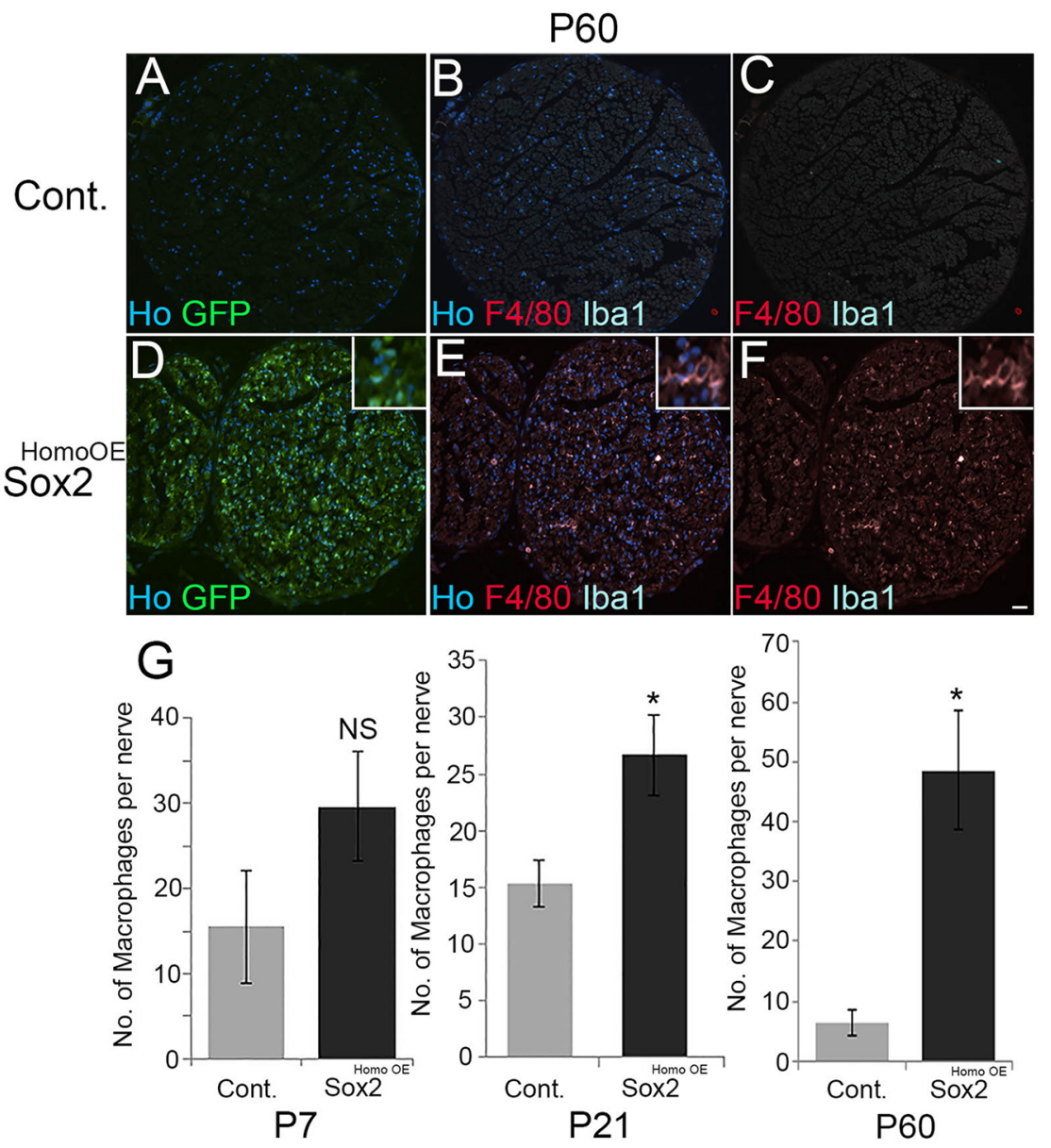

Fig. 8. Increased numbers of macrophages in intact P60 Sox $2^{\text {HomoOE }}$ sciatic nerves. (A-F) Double immunolabelling of $\mathrm{P} 60$ control (A-C) and Sox $2^{\text {HomoOE }}(D-F)$ sciatic nerves with F4/80 and Iba1 to identify macrophages. Scale bar: $40 \mu \mathrm{m}$. Insets in D-F show higher magnification of $\mathrm{F} 4 / 80 / \mathrm{lba} 1$ double-positive macrophages. (G) Quantification of macrophage numbers at P7, P21 and P60; a significant increase in macrophage numbers is observed in both P21 and P60 Sox2 HomooE nerves. Two-sided two-sample Student's t-test; data from $n=3$ mice of each genotype at each time point; ${ }^{*} P<0.05$.

of Necl4 function in SCs, either by shRNA knockdown or expression of a dominant-negative form of the protein, prevents normal SC-axon interaction, Krox20 induction and myelination in vitro (Maurel et al., 2007; Golan et al., 2013; Spiegel et al., 2007), but loss of Necl4 in vivo is associated with focal hypermyelination and a phenotype resembling several CMT subtypes (Golan et al., 2013). It is therefore unclear at present what role, if any, decreased Necl4 levels may play in the phenotype we observe in our Sox2 overexpressing animals.

Overexpression of the mammalian Lin28 homologue B (Lin28B) RNA-binding protein and reduction in the levels of the let-7 family of microRNAs in SCs has been shown to inhibit peripheral nerve myelination in vivo (Gokbuget et al., 2015). As Sox2 has been shown to increase Lin28B levels in embryonic stem cells and neural progenitors (Cimadamore et al., 2013; Marson et al., 2008), we measured Lin28B protein levels in control and Sox $2^{\mathrm{HomoOE}}$ nerves at P60. We do not detect Lin28B expression in either control or Sox $2^{\mathrm{HomoOE}}$ adult nerve (Fig. S2H); therefore, seemingly eliminating the Lin28B/let-7 signalling axis as mediating the Sox2-induced hypomyelination.

It is still unclear why the expression of the Sox2IRESGFP transgene declines in the Sox $2^{\mathrm{HetOE}}$ animals up to P21, as the construct is inserted into the Rosa26 locus and the construct also contains a synthetic cytomegalovirus early enhancer/chicken beta actin (CAG) promoter (Lu et al., 2010); but these issues of silencing of the transgene expression were not seen in the Sox $2^{\mathrm{HomoOE}}$ animals, allowing us to monitor the effects of Sox 2 expression up to P60 in these animals. Analysis of Sox $2^{\mathrm{HetOE}}$ nerves up to P60 allowed us to measure the effects of the removal of Sox2 overexpression in SCs from P21 onwards. In this case, the nerves continued their myelination and by P60 they appeared normally myelinated with G-ratios similar to control nerves, once again underlining a remarkable ability of SCs within the nerve to resume and complete their myelination programme.

The normal myelination observed in P60 Sox $2{ }^{\mathrm{HetOE}}$ nerves and re-activation of Sox 2 expression following injury in these animals also allowed us to confirm that Sox 2 negatively regulates both developmental myelination and re-myelination following injury, in contrast to some regulators within SCs that have developmental or repair-specific functions (Arthur-Farraj et al., 2012; Fontana et al., 2012; Kim et al., 2000; Jessen and Mirsky, 2016; Mindos et al., 2017).

Whether negative regulators of myelination play roles in the pathology of human peripheral neuropathies or mouse models of these conditions has been recently examined. Increased expression of the Jun transcription factor in SCs has been observed in patients with Charcot-Marie-Tooth (CMT) disease or chronic inflammatory demyelinating polyradiculopathy, and in mouse models of CMT (Saporta et al., 2012; Hutton et al., 2011; Hantke et al., 2014; Klein et al., 2014). Although it has been suggested that abnormal expression of Jun may be involved in the pathology of the hypomyelination seen (Saporta et al., 2012), recent work using the C3 mouse model of CMT1A showed that Jun expression was actually protective. Genetic removal of Jun in the $\mathrm{C} 3$ mouse, which models human CMT1A, led to a progressive loss of myelinated sensory axons and increasing sensory-motor loss (Hantke et al., 2014). Thus, as opposed to driving the neuropathy in these animals, raised expression of Jun in SCs is a protective mechanism that ameliorates 


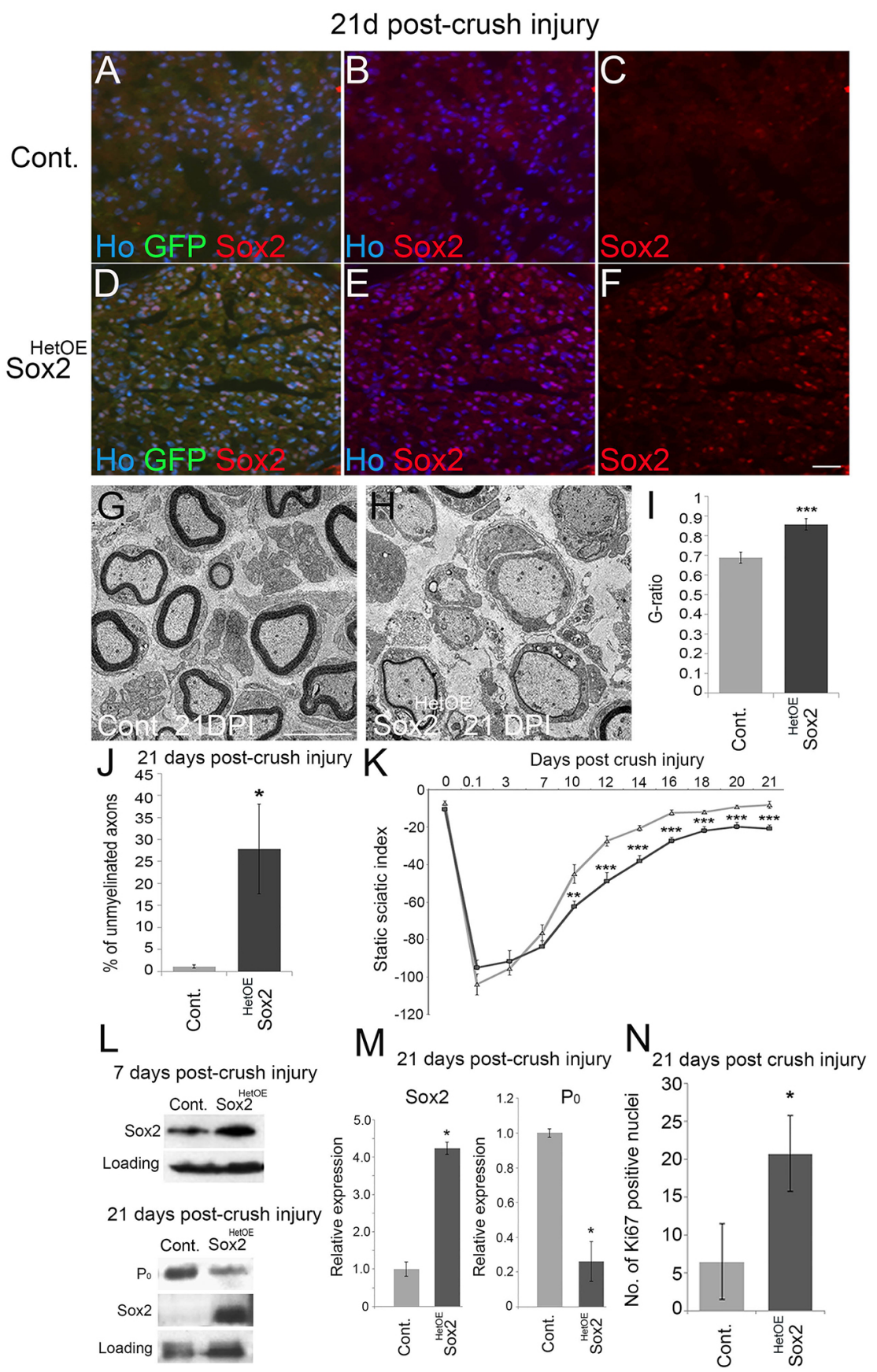

Fig. 9. Sustained Sox2 expression results in hypomyelination and reduced functional recovery following nerve injury. (A-F) Immunolabelling of distal nerve sections 21 days post-crush injury (DPI) revealed that nerves from control animals no longer expressed Sox2 at this time point (A-C), whereas Sox2 (and GFP) levels remained elevated in the distal sciatic nerves of injured Sox $2^{\text {HetOE }}$ mice (D-F). Scale bar: $40 \mu \mathrm{m}$.

$(\mathrm{G}, \mathrm{H})$ TEM pictures of distal nerve sections at $21 \mathrm{DPI}$ revealed that axons in control nerves are remyelinated $(G)$, whereas few axons are remyelinated in Sox $2^{\text {HetOE }}$ nerves $(\mathrm{H})$. Scale bar: $5 \mu \mathrm{m}$. (I) G-ratio measurements revealed that Sox $2^{\text {HetOE }}$ sciatic nerves were significantly hypomyelinated compared with control nerves at $21 \mathrm{DPI}$. $(\mathrm{J})$ There is a significant increase in the percentage of unmyelinated axons in Sox $2^{\mathrm{HetOE}}$ nerves compared with controls at $21 \mathrm{DPI}$. Two-sided two-sample Student's $t$-test; data from $n=3$ mice of each genotype. (K) Quantification of functional recovery by static sciatic index (SSI). Control, $n=5$; Sox $2^{\mathrm{HetOE}}, n=7$. Two-sided twosample Student's $t$-test. (L) Western blot showing high levels of Sox 2 at 7 and $21 \mathrm{DPI}$ and a reduction in $\mathrm{P}_{0}$ expression in Sox $2^{\mathrm{HetOE}}$ mice at $21 \mathrm{DPI}$. (M)

Quantification of western blots from L. Two-sided twosample Student's $t$-test; data from $n=3$ independent blots. (N) There is significant increase in the number of Ki67positive nuclei in distal Sox $2^{\mathrm{HetOE}}$ sciatic nerves at $21 \mathrm{DPI}$ Two-sided two-sample Student's $t$-test; data from $n=3$ mice of each genotype. ${ }^{*} P<0.05,{ }^{* *} P<0.005$

the disease state. Recent reports have shown that levels of Sox2 mRNA are elevated in mouse models of CMT types 1A and 1B (D'Antonio et al., 2013; Giambonini-Brugnoli et al., 2005), but any potential roles for this increased expression are currently unknown.

The finding of increased macrophage numbers within both the intact Sox $2^{\mathrm{HomoOE}}$ nerve at $\mathrm{P} 60$ and within the Sox $2^{\mathrm{HetOE}}$ nerve following injury suggests a role for Sox 2 in the control of macrophage entry to the nerve, although it is not clear whether this is a direct effect, or is due to the lack of myelination or the apparent ongoing myelin breakdown and axonal loss seen in the adult P60 Sox $2^{\mathrm{HomoOE}}$ nerves (Fig. 4F, G). In conclusion, we have identified that Sox 2 acts as an in vivo inhibitor of the myelinating phenotype of SCs and have shown new roles for this protein in both controlling the proliferation of SCs and recruitment of macrophages to the nerve.

\section{MATERIALS AND METHODS}

\section{Reagents}

Adenoviruses expressing Krox20/GFP, Sox2/GFP and GFP control have been previously described (Le et al., 2005; Nagarajan et al., 2001; Parkinson et al., 2004, 2008). Antibodies against Sox 2 were from Novus Biological (NB 11037235SS) for western blotting and from Millipore (AB5603) for immunostaining. Antibodies against myelin basic protein (MBP) (sc-13912), $\beta 2 \mathrm{~A}$ tubulin (sc-134229) and $\alpha 6$ integrin (F6) were from Santa Cruz Biotechnology. Antibodies to N-cadherin (610920), $\beta$-catenin (610163) and Jun (610327) were from Becton-Dickinson. Antibodies to Ki67 (Ab15580) and Sox10 (Ab155279) were from Abcam. Krox20 antibody (PRB-236P) was from Covance. Anti-laminin $\alpha 2$ antibody (ALX-804-190) was from Enzo. Antibodies against myelin protein zero $\left(\mathrm{P}_{0}\right)$, periaxin, Iba1, F4/80 and CD3 were as described previously (Archelos et al., 1993; Gillespie et al., 1994; Mindos et al., 2017; Napoli et al., 2012). For further details of primary antibodies used, see the supplementary Materials and Methods. Biotinylated 
antibodies, AlexaFluor fluorescently conjugated antibodies and fluorescently conjugated streptavidin were as previously described (Doddrell et al., 2013).

\section{Transgenic mice and genotyping}

Transgenic mouse breeding and experiments were carried out according to Home Office regulations under the UK Animals (Scientific Procedures) Act 1986. Ethical approval for experiments was granted by Plymouth University Animal Welfare and Ethical Review Board. To identify effects of Sox2 overexpression in SCs in vivo, we crossed homozygous Rosa26RSox2IRESGFP mice ( $\mathrm{Lu}$ et al., 2010) with P0-CRE ( $\mathrm{mP}_{0}$-TOTACRE) mice (Feltri et al., 1999). This generated heterozygous Rosa26 Sox2IRESGFP CRE-positive $(+)$ and CRE-negative $(-)$ offspring. Heterozygous Rosa26 Sox2IRESGFP $\mathrm{CRE}^{+}$animals were then backcrossed with homozygous Rosa26 Sox2IRESGFP CRE ${ }^{-}$mice to generate heterozygous and homozygous Rosa26R-Sox2IRESGFP CRE and $\mathrm{CRE}^{+}$mice. $\mathrm{CRE}^{+}$animals carrying one copy of the Rosa26 Sox2IRESGFP transgene are referred to as Sox $2^{\mathrm{HetOE}}$; $\mathrm{CRE}^{+}$animals carrying two copies of the Rosa26 Sox2IRESGFP transgene are referred to as Sox $2^{\mathrm{HomoOE}}$ mice. For analysis of both $\mathrm{Sox} 2^{\mathrm{HetOE}}$ and $\mathrm{Sox} 2^{\mathrm{HomoOE}}$ mice, age and sex-matched $\mathrm{CRE}^{-}$animals of the same Rosa26 Sox2IRESGFP transgene status are used as controls. For mouse genotyping, genomic DNA was extracted using the HotSHOT method and analysed as previously described (Lu et al., 2010; Feltri et al., 1999; Truett et al., 2000).

\section{Nerve injury}

For nerve crush injury, the right sciatic nerve was compressed using round end forceps, as previously described (Dun and Parkinson, 2015). The left sciatic nerve was left uninjured. Mice were euthanized at the indicated time, and both uninjured contralateral and injured distal sciatic nerves collected for analysis.

\section{Cell culture and adenoviral/retroviral infection}

Rat SCs were prepared from postnatal day 3 rats, as described previously (Brockes et al., 1979; Parkinson et al., 2001). SCs were infected with GFP/ Krox-20 (GFP/K20) (Parkinson et al., 2004; Nagarajan et al., 2001), control GFP or GFP/Sox 2 adenovirus (Le et al., 2005) or both GFP/Sox2 and GFP/ $\mathrm{K} 20$ (Sox $2 / \mathrm{K} 20$ ) adenovirus for $24 \mathrm{~h}$ in defined medium (DM) (Jessen et al., 1994) then incubated for a further $24 \mathrm{~h}$ in $\mathrm{DM}$ before fixing and immunolabelling. For details of DRG/Schwann cell culture and co-culture, retroviral/lentiviral constructs and infection, RNA preparation and semiquantitative PCR, please see the supplementary Materials and Methods.

\section{Immunocytochemistry, immunohistochemistry and western blotting}

SCs were cultured on poly L-lysine/laminin-coated glass coverslips as previously described (Jessen et al., 1994). For immunohistochemical analysis of sections, nerves were fixed in $4 \% \mathrm{w} / \mathrm{v}$ paraformaldehyde and embedded for cryosectioning. All staining, antibodies, counts and confocal and fluorescence microscopy were as described previously (Doddrell et al., 2013; Parkinson et al., 2008, 2003). Anti-MBP (1:100) and anti-Ki67 (1:200) antibodies were diluted in antibody diluting solution with $0.2 \%$ Triton X-100 and incubated overnight at $4{ }^{\circ} \mathrm{C}$. For western blotting, nerve samples were lysed in SDS buffer and electrophoresed on SDSpolyacrylamide gels (Doddrell et al., 2013; Parkinson et al., 2004, 2008, 2003). $\beta 2 \mathrm{~A}$ tubulin was used as loading control for western blots.

\section{Transmission electron microscopy}

Nerves were fixed in $2.5 \%$ glutaraldehyde in $0.1 \mathrm{M}$ phosphate buffer ( $\mathrm{pH} 7.2$ ), post-fixed in $1 \%$ osmium tetroxide, dehydrated and embedded in resin. Semithin sections were cut using a glass knife and stained with Toluidine Blue. Ultra-thin sections were cut and stained with uranyl acetate and lead citrate. Sections were photographed using a JEOL 1200EX or 1400 TEM microscope. For details of electron microscopy analysis of SC/DRG co-cultures and SCs, see the supplementary Materials and Methods. For quantification of the $\mathrm{G}$ ratio in intact and injured nerves, axon diameter and fibre (axon+myelin) diameter were measured from 200 axons from each animal using Image J, which allowed for myelin thickness and G-ratio calculation. For quantification of numbers of myelinated/degenerated fibres per field, average counts were made from five separate fields from both P60 control and Sox $2^{\mathrm{HomoOE}}$ nerves.

\section{Functional testing}

Motor capacity in 6- and 8-week-old mice was assessed by rotarod analysis. Rotarod training and final testing was as previously described (Saporta et al., 2012; Kuhn et al., 1995). (Rods accelerated from 2 to 30 rotations per minute over $250 \mathrm{~s}$.)

For nerve conduction velocity (NCV) measurements, sciatic nerves from P21 or P90 animals were dissected and placed into a perfusion chamber for 30-45 min before measurements were initiated. During this time the sciatic nerves were incubated at $37^{\circ} \mathrm{C}$, and perfused with artificial cerebrospinal fluid (aCSF) as described previously (Fern et al., 1998; Alix and Fern, 2009). The distal ends of the sciatic nerves were positioned within an aCSF-filled glass stimulating electrode and compound action potentials (CAP) were induced (Alix and Fern, 2009). CAPs were recorded by the second recording aCSFfilled glass electrode surrounding the proximal end of the sciatic nerve (Fern et al., 1998) and displayed using Signal software (Cambridge Electronic Design). NCVs were calculated using two parameters: (1) the length of the stimulated nerve; and (2) the time difference between the start of the stimulus artefact to the peak of the CAP. Measurements of sensory function on control and Sox $2^{\mathrm{HomoOE}}$ animals were performed using Von Fray filament and toe pinch tests; for more details see the supplementary Materials and Methods.

Functional recovery was measured on mice following injury using the static sciatic index (SSI) measurement. Paw print measurements were taken using a video camera from each mouse before surgery ( 0 days) and up to 21 days following injury to calculate the SSI (Baptista et al., 2007).

\section{Statistics}

For all experiments, $n=3$ unless otherwise stated. Graphs display the arithmetic mean with error bars representing one standard error of the mean. Statistical analysis was carried out using Student's $t$-test and $P$ values are used to denote significance: ${ }^{*} P<0.05,{ }^{* *} P<0.01,{ }^{* * *} P<0.005$.

Owing to small sample sizes ( $n<5$ for most comparisons), how well normality and equal variances fitted the data could not be reliably assessed. Sample size was not predetermined by statistical methods and randomisation was not applied. For functional testing using the SSI, the evaluation was made by an individual blinded to the animal genotype. No samples or data were excluded from the analysis. The $n$ value for each experiment is stated in the appropriate figure legend.

\section{Acknowledgements}

We are grateful for excellent technical support from Mr Peter Bond, Mr Glenn Harper and Dr Roy Moate in the Plymouth University EM Centre and to Ms Cinzia Ferri and Dr Mariacarla Panzeri at the ALEMBIC service at the San Raffaele for help with TEM sample processing and imaging. We thank Prof. Bob Fern, Dr Angelo de Rosa and Mr Sean Doyle (Plymouth University) for help with electrophysiology measurements. We also thank Profs Laura Feltri and Larry Wrabetz (University of New York at Buffalo, USA) for providing the $\mathrm{mP}_{0}$-TOTACRE mice. We are grateful to Mr W. Woznica for excellent technical support with animal husbandry for the study.

\section{Competing interests}

The authors declare no competing or financial interests.

\section{Author contributions}

Conceptualization: D.B.P., X.P.D., S.L.R., A.C.L.; Methodology: D.B.P., X.P.D., F.F., M.D., S.L.R.; Validation: D.B.P., M.D., S.L.R.; Formal analysis: D.B.P., X.P.D., L.K.D., M.D., S.L.R.; Investigation: D.B.P., X.P.D., R.D.S.D., T.M., L.K.D., F.F., A.Q., M.D., S.L.R.; Resources: D.B.P., X.P.D., M.W.O.; Data curation: D.B.P., X.P.D., R.D.S.D., T.M., L.K.D., S.L.R.; Writing - original draft: D.B.P.; Writing - review \& editing: D.B.P., X.P.D., M.D., S.L.R.; Visualization: D.B.P., X.P.D., R.D.S.D., T.M., A.Q., S.L.R.; Supervision: D.B.P., M.D.; Project administration: D.B.P., X.P.D. Funding acquisition: D.B.P., M.D., A.C.L.

Funding

This work was supported by a grant from the Wellcome Trust (088228/Z/09/Z to D.B.P.; A.C.L.). M.D. is supported by Fondazione Telethon (GGP14147) and the Italian Ministry of Health (Ministero della Salute) (GR-2011-02346791). Deposited in PMC for release after 6 months.

\section{Supplementary information}

Supplementary information available online at http://dev.biologists.org/lookup/doi/10.1242/dev.150656.supplemental 


\section{References}

Alix, J. J. P. and Fern, R. (2009). Glutamate receptor-mediated ischemic injury of premyelinated central axons. Ann. Neurol. 66, 682-693.

Archelos, J. J., Roggenbuck, K., Scheider-Schaulies, J., Linington, C., Toyka, K. V. and Hartung, H. P. (1993). Production and kcharacterization of monoclonal antibodies to the extracellular domain of P0. J. Neurosci. Res. 35, 46-53.

Arthur-Farraj, P., Mirsky, R., Parkinson, D. B. and Jessen, K. R. (2006). A double point mutation in the DNA-binding region of Egr2 switches its function from inhibition to induction of proliferation: A potential contribution to the development of congenital hypomyelinating neuropathy. Neurobiol. Dis. 24, 159-169.

Arthur-Farraj, P. J., Latouche, M., Wilton, D. K., Quintes, S., Chabrol, E., Banerjee, A., Woodhoo, A., Jenkins, B., Rahman, M., Turmaine, M. et al. (2012). c-Jun reprograms Schwann cells of injured nerves to generate a repair cell essential for regeneration. Neuron 75, 633-647.

Baloh, R. H., Strickland, A., Ryu, E., Le, N., Fahrner, T., Yang, M., Nagarajan, R. and Milbrandt, J. (2009). Congenital hypomyelinating neuropathy with lethal conduction failure in mice carrying the Egr2 I268N mutation. J. Neurosci. 29 2312-2321.

Baptista, A. F., Gomes, J. R. D. S., Oliveira, J. T., Santos, S. M. G. Vannier-Santos, M. A. and Martinez, A. M. B. (2007). A new approach to assess function after sciatic nerve lesion in the mouse - Adaptation of the sciatic static index. J. Neurosci. Methods 161, 259-264

Brockes, J. P., Fields, K. L. and Raff, M. C. (1979). Studies on cultured rat Schwann cells. I. Establishment of purified populations from cultures of peripheral nerve. Brain Res. 165, 105-118.

Cimadamore, F., Amador-Arjona, A., Chen, C., Huang, C. T. and Terskikh, A. V. (2013). SOX2-LIN28/let-7 pathway regulates proliferation and neurogenesis in neural precursors. Proc. Natl. Acad. Sci. USA 110, E3017-E3026.

Crawford, A. T., Desai, D., Gokina, P., Basak, S. and Kim, H. A. (2008) E-cadherin expression in postnatal Schwann cells is regulated by the cAMPdependent protein kinase a pathway. Glia 56, 1637-1647

D’Antonio, M., Musner, N., Scapin, C., Ungaro, D., Del Carro, U., Ron, D., Feltri, M. L. and Wrabetz, L. (2013). Resetting translational homeostasis restores myelination in Charcot-Marie-Tooth disease type 1B mice. J. Exp. Med. 210 821-838

Desmazieres, A., Decker, L., Vallat, J.-M., Charnay, P. and Gilardi-Hebenstreit, P. (2008). Disruption of Krox20-Nab interaction in the mouse leads to peripheral neuropathy with biphasic evolution. J. Neurosci. 28, 5891-5900.

Doddrell, R. D. S., Dun, X.-P., Moate, R. M., Jessen, K. R., Mirsky, R. and Parkinson, D. B. (2012). Regulation of Schwann cell differentiation and proliferation by the Pax-3 transcription factor. Glia 60, 1269-1278.

Doddrell, R. D. S., Dun, X.-P., Shivane, A., Feltri, M. L., Wrabetz, L., Wegner, M., Sock, E., Hanemann, C. O. and Parkinson, D. B. (2013). Loss of SOX10 function contributes to the phenotype of human Merlin-null schwannoma cells. Brain 136, 549-563.

Dun, X. P. and Parkinson, D. B. (2015). Visualizing peripheral nerve regeneration by whole mount staining. PLoS One 10, e0119168.

Feltri, M. L., D'Antonio, M., Previtali, S., Fasolini, M., Messing, A. and Wrabetz, L. (1999). P0-Cre transgenic mice for inactivation of adhesion molecules in Schwann cells. Ann. N. Y. Acad. Sci. 883, 116-123.

Fern, R., Davis, P., Waxman, S. G. and Ransom, B. R. (1998). Axon conduction and survival in CNS white matter during energy deprivation: a developmental study. J. Neurophysiol. 79, 95-105.

Finzsch, M., Schreiner, S., Kichko, T., Reeh, P., Tamm, E. R., Bösl, M. R., Meijer, D. and Wegner, M. (2010). Sox10 is required for Schwann cell identity and progression beyond the immature Schwann cell stage. J. Cell Biol. 189, 701-712.

Fontana, X., Hristova, M., Da Costa, C., Patodia, S., Thei, L., Makwana, M., Spencer-Dene, B., Latouche, M., Mirsky, R., Jessen, K. R. et al. (2012). C-Jun in Schwann cells promotes axonal regeneration and motoneuron survival via paracrine signaling. J. Cell Biol. 198, 127-141.

Fröb, F., Bremer, M., Finzsch, M., Kichko, T., Reeh, P., Tamm, E. R., Charnay, P. and Wegner, M. (2012). Establishment of myelinating Schwann cells and barrier integrity between central and peripheral nervous systems depend on Sox10. Glia 60, 806-819.

Funalot, B., Topilko, P., Arroyo, M. A., Sefiani, A., Hedley-Whyte, E. T., Yoldi, M. E., Richard, L., Touraille, E., Laurichesse, M., Khalifa, E. et al. (2012) Homozygous deletion of an EGR2 enhancer in congenital amyelinating neuropathy. Ann. Neurol. 71, 719-723.

Gess, B., Halfter, H., Kleffner, I., Monje, P., Athauda, G., Wood, P. M., Young, P. and Wanner, I. B. (2008). Inhibition of $\mathrm{N}$-cadherin and beta-catenin function reduces axon-induced Schwann cell proliferation. J. Neurosci. Res. 86, 797-812.

Giambonini-Brugnoli, G., Buchstaller, J., Sommer, L., Suter, U. and Mantei, N. (2005). Distinct disease mechanisms in peripheral neuropathies due to altered peripheral myelin protein 22 gene dosage or a Pmp22 point mutation. Neurobiol. Dis. 18, 656-668.

Gillespie, C. S., Sherman, D. L., Blair, G. E. and Brophy, P. J. (1994). Periaxin, a novel protein of myelinating schwann cells with a possible role in axonal ensheathment. Neuron 12, 497-508.
Gokbuget, D., Pereira, J. A., Bachofner, S., Marchais, A., Ciaudo, C., Stoffel, M. Schulte, J. H. and Suter, U. (2015). The Lin28/let-7 axis is critical for myelination in the peripheral nervous system. Nat. Commun. 6, 8584

Golan, N., Kartvelishvily, E., Spiegel, I., Salomon, D., Sabanay, H., Rechav, K. Vainshtein, A., Frechter, S., Maik-Rachline, G., Eshed-Eisenbach, Y. et al (2013). Genetic deletion of Cadm4 results in myelin abnormalities resembling Charcot-Marie-Tooth neuropathy. J. Neurosci. 33, 10950-10961.

Hantke, J., Carty, L., Wagstaff, L. J., Turmaine, M., Wilton, D. K., Quintes, S. Koltzenburg, M., Baas, F., Mirsky, R. and Jessen, K. R. (2014). c-Jun activation in Schwann cells protects against loss of sensory axons in inherited neuropathy Brain 137, 2922-2937.

Harrisingh, M. C., Perez-Nadales, E., Parkinson, D. B., Malcolm, D. S., Mudge, A. W. and Lloyd, A. C. (2004). The Ras/Raf/ERK signalling pathway drives Schwann cell dedifferentiation. EMBO J. 23, 3061-3071.

Hutton, E. J., Carty, L., Laura, M., Houlden, H., Lunn, M. P., Brandner, S., Mirsky, R., Jessen, K. and Reilly, M. M. (2011). C-Jun expression in human neuropathies: a pilot study. J. Peripher. Nerv. Syst. 16, 295-303.

Ishii, A., Furusho, M. and Bansal, R. (2013). Sustained activation of ERK1/2 MAPK in oligodendrocytes and schwann cells enhances myelin growth and stimulates oligodendrocyte progenitor expansion. J. Neurosci. 33, 175-186

Ishii, A., Furusho, M., Dupree, J. L. and Bansal, R. (2016). Strength of ERK1/2 MAPK activation determines its effect on myelin and axonal integrity in the adult CNS. J. Neurosci. 36, 6471-6487.

Jaegle, M., Mandemakers, W., Broos, L., Zwart, R., Karis, A., Visser, P. Grosveld, F. and Meijer, D. (1996). The POU factor Oct-6 and Schwann cell differentiation. Science 273, 507-510.

Jessen, K. R. and Mirsky, R. (2008). Negative regulation of myelination: relevance for development, injury, and demyelinating disease. Glia 56, 1552-1565.

Jessen, K. R. and Mirsky, R. (2016). The repair Schwann cell and its function in regenerating nerves. J. Physiol. 594, 3521-3531.

Jessen, K. R., Brennan, A., Morgan, L., Mirsky, R., Kent, A., Hashimoto, Y. and Gavrilovic, J. (1994). The Schwann cell precursor and its fate: a study of cell death and differentiation during gliogenesis in rat embryonic nerves. Neuron 12 509-527.

Kao, S. C., Wu, H., Xie, J., Chang, C. P., Ranish, J. A., Graef, I. A. and Crabtree, G. R. (2009). Calcineurin/NFAT signaling is required for neuregulin-regulated Schwann cell differentiation. Science 323, 651-654.

Kim, H. A., Pomeroy, S. L., Whoriskey, W., Pawlitzky, I., Benowitz, L. I., Sicinski, P., Stiles, C. D. and Roberts, T. M. (2000). A developmentally regulated switch directs regenerative growth of Schwann cells through cyclin D1. Neuron 26 , 405-416.

Klein, D., Groh, J., Wettmarshausen, J. and Martini, R. (2014). Nonuniform molecular features of myelinating Schwann cells in models for CMT1: distinct disease patterns are associated with NCAM and c-Jun upregulation. Glia 62 736-750

Kuhn, P. L., Petroulakis, E., Zazanis, G. A. and Mckinnon, R. D. (1995). Motor function analysis of myelin mutant mice using a rotarod. Int. J. Dev. Neurosci. 13 715-722.

Le, N., Nagarajan, R., Wang, J. Y., Araki, T., Schmidt, R. E. and Milbrandt, J. (2005). Analysis of congenital hypomyelinating Egr2Lo/Lo nerves identifies Sox2 as an inhibitor of Schwann cell differentiation and myelination. Proc. Natl. Acad. Sci. USA 102, 2596-2601.

Lewallen, K. A., Shen, Y. A., De la Torre, A. R., Ng, B. K., Meijer, D. and Chan, J. R. (2011). Assessing the role of the cadherin/catenin complex at the Schwann cell-axon interface and in the initiation of myelination. $J$ Neurosci. 31, 3032-3043.

Lu, Y., Futtner, C., Rock, J. R., Xu, X., Whitworth, W., Hogan, B. L. and Onaitis, M. W. (2010). Evidence that SOX2 overexpression is oncogenic in the lung. PLoS ONE 5, e11022.

Marson, A., Levine, S. S., Cole, M. F., Frampton, G. M., Brambrink, T., Johnstone, S., Guenther, M. G., Johnston, W. K., Wernig, M., Newman, J. et al. (2008) Connecting microRNA genes to the core transcriptional regulatory circuitry of embryonic stem cells. Cell 134, 521-533.

Maurel, P., Einheber, S., Galinska, J., Thaker, P., Lam, I., Rubin, M. B., Scherer, S. S., Murakami, Y., Gutmann, D. H. and Salzer, J. L. (2007). Nectin-like proteins mediate axon Schwann cell interactions along the internode and are essential for myelination. J. Cell Biol. 178, 861-874

Mindos, T., Dun, X. P., North, K., Doddrell, R. D., Schulz, A., Edwards, P., Russell, J., Gray, B., Roberts, S. L., Shivane, A. et al. (2017). Merlin controls the repair capacity of Schwann cells after injury by regulating Hippo/YAP activity. J. Cell Biol. 216, 495-510.

Nagarajan, R., Svaren, J., Le, N., Araki, T., Watson, M. and Milbrandt, J. (2001) EGR2 mutations in inherited neuropathies dominant-negatively inhibit myelin gene expression. Neuron 30, 355-368

Napoli, I., Noon, L. A., Ribeiro, S., Kerai, A. P., Parrinello, S., Rosenberg, L. H. Collins, M. J., Harrisingh, M. C., White, I. J., Woodhoo, A. et al. (2012). A central role for the ERK-signaling pathway in controlling Schwann cell plasticity and peripheral nerve regeneration in vivo. Neuron 73, 729-742.

Parkinson, D. B., Dong, Z., Bunting, H., Whitfield, J., Meier, C., Marie, H., Mirsky, R. and Jessen, K. R. (2001). Transforming growth factor $\beta$ (TGF $\beta$ ) mediates schwann cell death in vitro and in vivo: examination of c-Jun activation, 
interactions with survival signals, and the relationship of TGF $\beta$-mediated death to schwann cell differentiation. J. Neurosci. 21, 8572-8585.

Parkinson, D. B., Dickinson, S., Bhaskaran, A., Kinsella, M. T., Brophy, P. J., Sherman, D. L., Sharghi-Namini, S., Duran Alonso, M. B., Mirsky, R. and Jessen, K. R. (2003). Regulation of the myelin gene periaxin provides evidence for Krox-20-independent myelin-related signalling in Schwann cells. Mol. Cell. Neurosci. 23, 13-27.

Parkinson, D. B., Bhaskaran, A., Droggiti, A., Dickinson, S., D'antonio, M., Mirsky, R. and Jessen, K. R. (2004). Krox-20 inhibits Jun-NH2-terminal kinase/ C-Jun to control Schwann cell proliferation and death. J. Cell Biol. 164, 385-394.

Parkinson, D. B., Bhaskaran, A., Arthur-Farraj, P., Noon, L. A., Woodhoo, A., Lloyd, A. C., Feltri, M. L., Wrabetz, L., Behrens, A., Mirsky, R. et al. (2008). C-Jun is a negative regulator of myelination. J. Cell Biol. 181, 625-637.

Parrinello, S., Napoli, I., Ribeiro, S., Digby, P. W., Fedorova, M., Parkinson, D. B., Doddrell, R. D. S., Nakayama, M., Adams, R. H. and Lloyd, A. C. (2010). EphB signaling directs peripheral nerve regeneration through Sox2-dependent Schwann cell sorting. Cell 143, 145-155.

Roberts, S. L., Dun, X. P., Dee, G., Gray, B., Mindos, T. and Parkinson, D. B. (2016). The role of p38alpha in Schwann cells in regulating peripheral nerve myelination and repair. J. Neurochem. 141, 37-47.

Saporta, M. A., Shy, B. R., Patzko, A., Bai, Y., Pennuto, M., Ferri, C., Tinelli, E., Saveri, P., Kirschner, D., Crowther, M. et al. (2012). MpzR98C arrests Schwann cell development in a mouse model of early-onset Charcot-Marie-Tooth disease type 1B. Brain 135, 2032-2047.

Spiegel, I., Adamsky, K., Eshed, Y., Milo, R., Sabanay, H., Sarig-Nadir, O. Horresh, I., Scherer, S. S., Rasband, M. N. and Peles, E. (2007). A central role for Necl4 (SynCAM4) in Schwann cell-axon interaction and myelination. Nat. Neurosci. 10, 861-869.

Svaren, J. and Meijer, D. (2008). The molecular machinery of myelin gene transcription in Schwann cells. Glia 56, 1541-1551.
Topilko, P., Schneider-Maunoury, S., Levi, G., Baron-Van Evercooren, A., Chennoufi, A. B., Seitanidou, T., Babinet, C. and Charnay, P. (1994). Krox-20 controls myelination in the peripheral nervous system. Nature 371, 796-799.

Truett, G. E., Heeger, P., Mynatt, R. L., Truett, A. A., Walker, J. A. and Warman, M. L. (2000). Preparation of PCR-quality mouse genomic DNA with hot sodium hydroxide and tris (HotSHOT). BioTechniques 29, 52-54

Wanner, I. B. and Wood, P. M. (2002). N-cadherin mediates axon-aligned process growth and cell-cell interaction in rat Schwann cells. J. Neurosci. 22, 4066-4079.

Warner, L. E., Mancias, P., Butler, I. J., Mcdonald, C. M., Keppen, L., Koob, K. G. and Lupski, J. R. (1998). Mutations in the early growth response 2 (EGR2) gene are associated with hereditary myelinopathies. Nat. Genet. 18, 382-384.

Warner, L. E., Svaren, J., Milbrandt, J. and Lupski, J. R. (1999). Functional consequences of mutations in the early growth response 2 gene (EGR2) correlate with severity of human myelinopathies. Hum. Mol. Genet. 8, 1245-1251.

Wanner, I. B., Guerra, N. K., Mahoney, J., Kumar, A., Wood, P. M., Mirsky, R. and Jessen, K. R. (2006). Role of N-cadherin in Schwann cell precursors of growing nerves. Glia 54, 439-459.

Woodhoo, A., Alonso, M. B., Droggiti, A., Turmaine, M., D'antonio, M., Parkinson, D. B., Wilton, D. K., Al-Shawi, R., Simons, P., Shen, J. et al. (2009). Notch controls embryonic Schwann cell differentiation, postnatal myelination and adult plasticity. Nat. Neurosci. 12, 839-847.

Wrabetz, L., D'Antonio, M., Pennuto, M., Dati, G., Tinelli, E., Fratta, P., Previtali, S., Imperiale, D., Zielasek, J., Toyka, K. et al. (2006). Different intracellular pathomechanisms produce diverse Myelin Protein Zero neuropathies in transgenic mice. J. Neurosci. 26, 2358-2368.

Yang, D. P., Kim, J., Syed, N., Tung, Y. J., Bhaskaran, A., Mindos, T., Mirsky, R., Jessen, K. R., Maurel, P., Parkinson, D. B. et al. (2012). p38 MAPK activation promotes denervated Schwann cell phenotype and functions as a negative regulator of Schwann cell differentiation and myelination. J. Neurosci. 32, 7158-7168. 


\section{Supplementary information; Roberts et al.}

Sox2 expression in Schwann cells inhibits myelination in vivo and induces influx of macrophages to the nerve.

Sheridan Roberts ${ }^{1 *}$, Xin-peng Dun ${ }^{1 *}$, Robin D. S. Doddrell ${ }^{1}$,Thomas Mindos ${ }^{1}$, Mark W. Onaitis ${ }^{2}$, Louisa K. Drake ${ }^{3}$, Francesca Florio ${ }^{4}$, Angelo Quattrini ${ }^{4}$, Maurizio D’Antonio ${ }^{4}$ and David B. Parkinson ${ }^{1 *}$.

1. Plymouth University Peninsula Schools of Medicine and Dentistry, John Bull Building, Plymouth Science Park, Plymouth, PL6 8BU, UK.

2. University of California, San Diego, USA.

3. University of Bath, Bath BA2 7AY, England, UK

4. Division of Genetics and Cell Biology, San Raffaele Scientific Institute, DIBIT, 20132 Milan, Italy. 


\section{Supplementary Figures}

P7
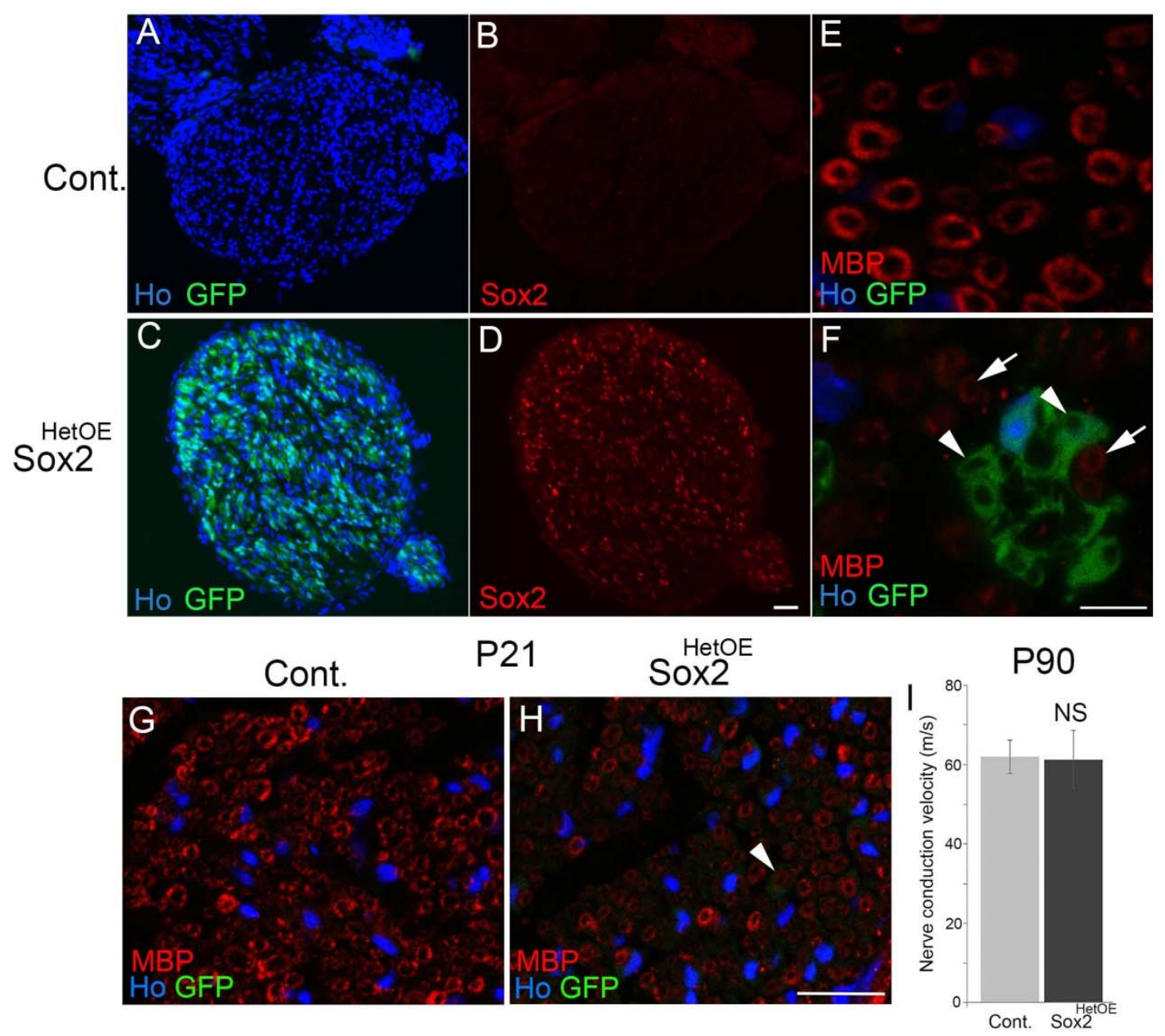

P60
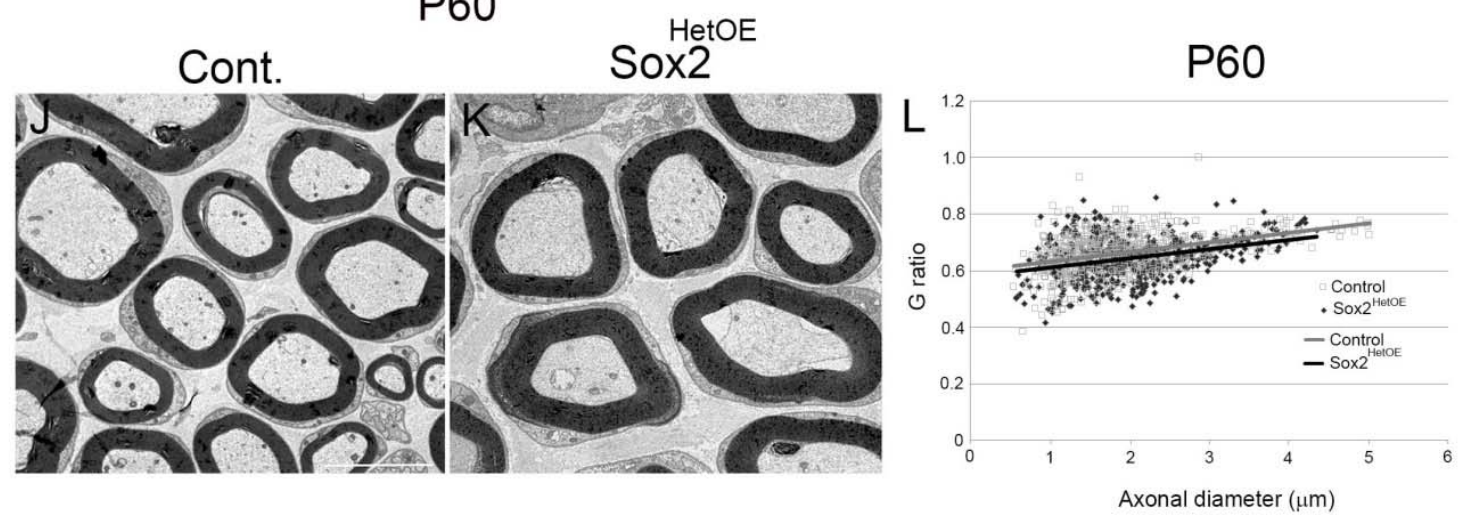

Figure S1: Analysis of Sox2 overexpressing nerves at P7, P21 and P60, showing post-natal decrease in transgene expression and normalisation of myelination at P60. A-D. Immunolabelling of control $(A, B)$ and Sox $2^{\text {HetOE }}(C, D)$ sciatic nerves with Sox2 
antibody showing both GFP and Sox2 expression in the Sox ${ }^{\text {HetOE }}$ nerve sections. Scale bar $20 \mu \mathrm{m}$. E, F. Immunolabelling of P7 control $(E)$ and Sox $2^{\text {HetOE }}(F)$ nerves showing myelin basic protein (MBP) expression. GFP expressing Schwann cells (arrowheads) show no MBP expression, whereas GFP negative cells (arrows) in the nerve are MBP positive. Scale bar $5 \mu \mathrm{m} . \mathrm{G}, \mathrm{H}$. Immunolabelling of P21 control (G) and Sox $2^{\text {HetOE }}(\mathrm{H})$ nerves showing MBP expression; a single weakly GFP-positive cell is indicated (arrowhead). Scale bar $25 \mu \mathrm{m}$. I. Measurement of nerve conduction velocity in P90 control and Sox $2^{\mathrm{HetOE}}$ nerves. Two sided two sample Student's t test; data from $n=3$ mice of each genotype. J, K. Transmission electron microscopy (TEM) pictures of P60 control $(\mathrm{J})$ and Sox $2^{\mathrm{HetOE}}(\mathrm{K})$ nerves. Scale bar $5 \mu \mathrm{m}$. L. Scatter plot of $\mathrm{G}$ ratio versus axonal diameter for $\mathrm{P} 60$ control and Sox $2^{\mathrm{HetOE}}$ nerves. 


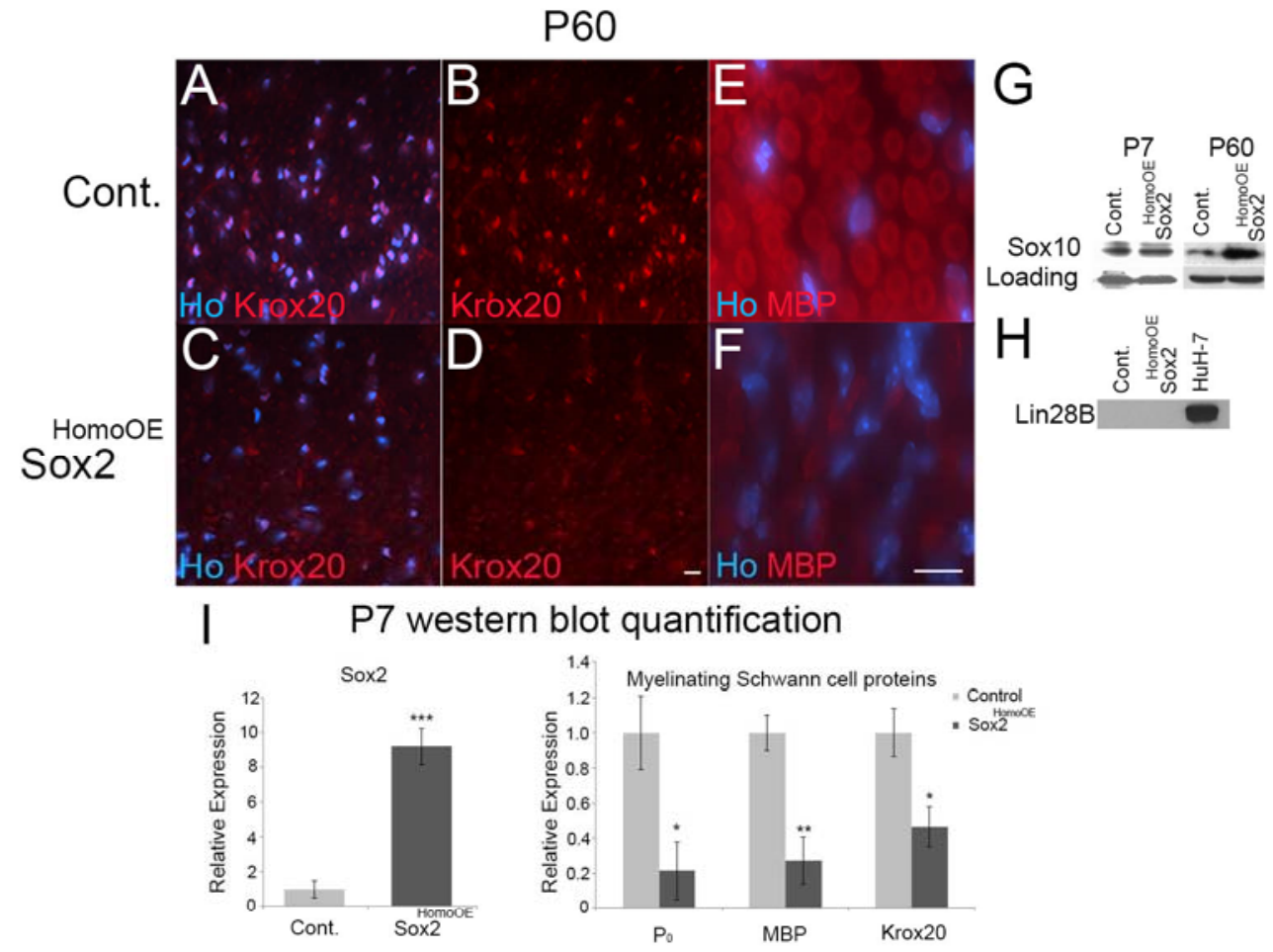

P60 western blot quantification
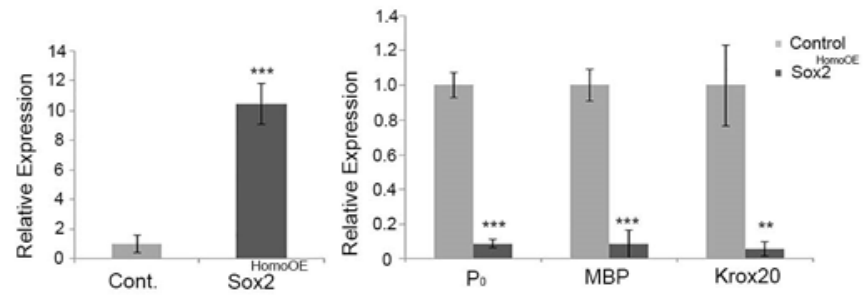

Figure S2: Analysis of P60 Sox ${ }^{\mathrm{HomoOE}}$ nerves. A-D. Immunolabelling of P60 control $(A, B)$ and Sox2 ${ }^{\text {HomoOE }}(C, D)$ nerves with Krox20 antibody revealed fewer Krox20 positive nuclei in Sox $2^{\text {HomoOE }}$ sections; sections are counterstained with Hoechst dye (Ho) to reveal nuclei. Scale bar $20 \mu \mathrm{m}$. E, F. Immunolabelling with myelin basic protein (MBP) antibody on P60 control $(E)$ and Sox2 ${ }^{\text {HomoOE }}(F)$ nerves. Scale bar $20 \mu \mathrm{m}$. G. Western blots of control and Sox $2^{\text {HomoOE }} \mathrm{P} 7$ and P60 nerves with Sox10 antibody. H. Western blot of P60 control and Sox2 ${ }^{\text {HomoOE }}$ nerves with Lin28B antibody. Cell extract from the hepatoma cell line $\mathrm{HuH}-7$ was used as a positive 
control for Lin28B protein expression. I. Quantification of western blots from Figure $3 \mathrm{~K}$ for control (Cont.) and Sox2 ${ }^{\text {HomoOE }}$ nerves. Two sided two sample Student's $\mathrm{t}$ test; data from 3 independent blots. 


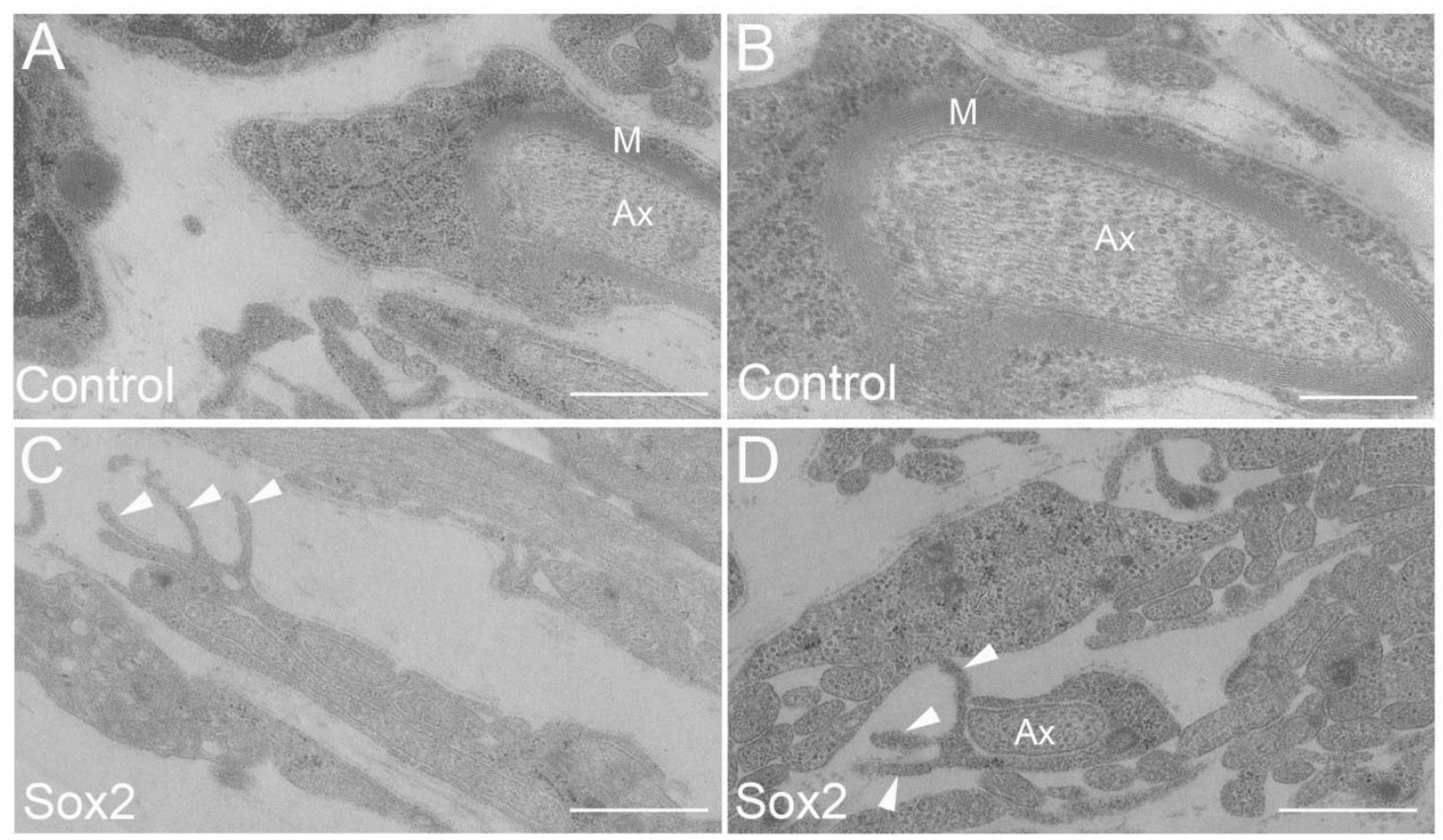

Figure S3: TEM images of Schwann cell/DRG neuron co-cultures. A, B. Control GFP infected Schwann cells show a normal contact with axons and myelin formation at 21 days post-ascorbic acid treatment (Panel B enlargement of Panel A). By contrast, Sox2 infected Schwann cells (C, D) do not complete axon ensheathment and still protrude cytoplasmic processes in the area at this timepoint (arrowheads in panels $C$ and D). M: myelin; Ax: Axon. Scale bars A, C and D: $1 \mu \mathrm{m}$; B: 500nm. 
A Toe pinch test

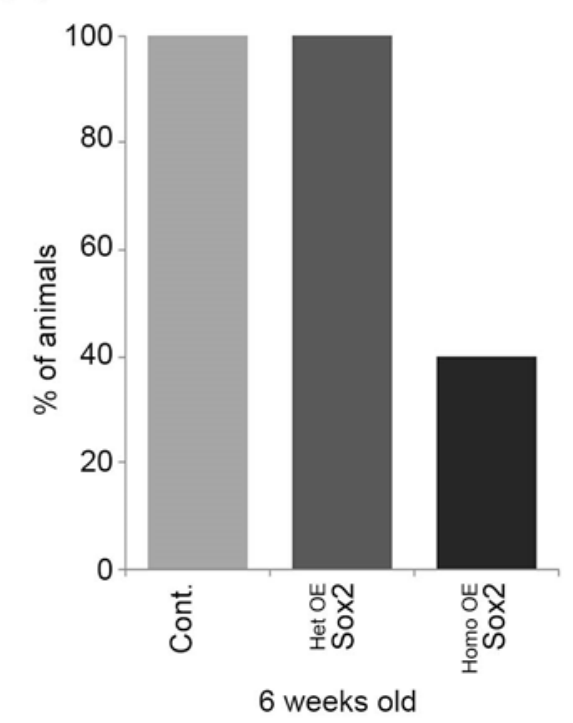

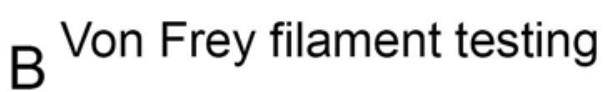

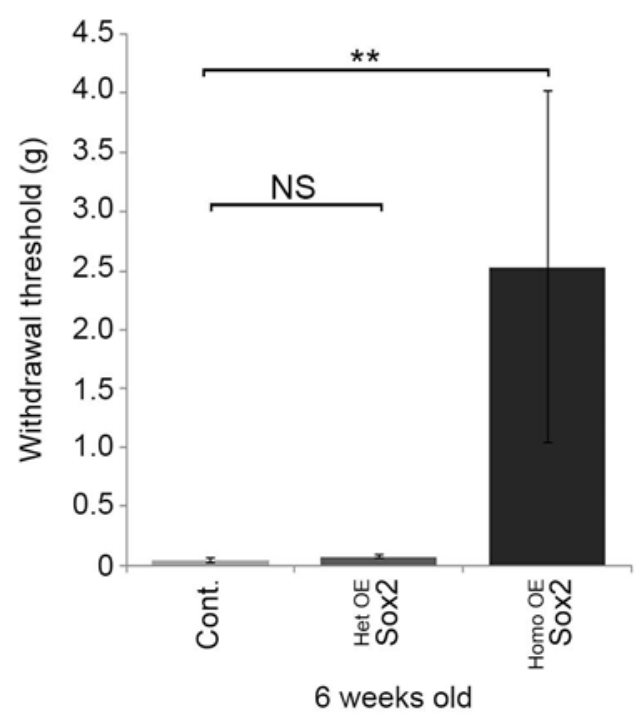

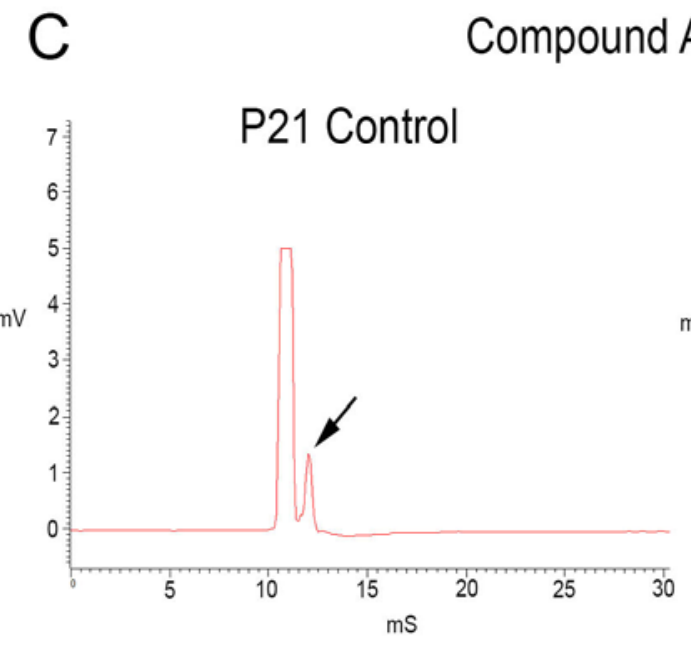

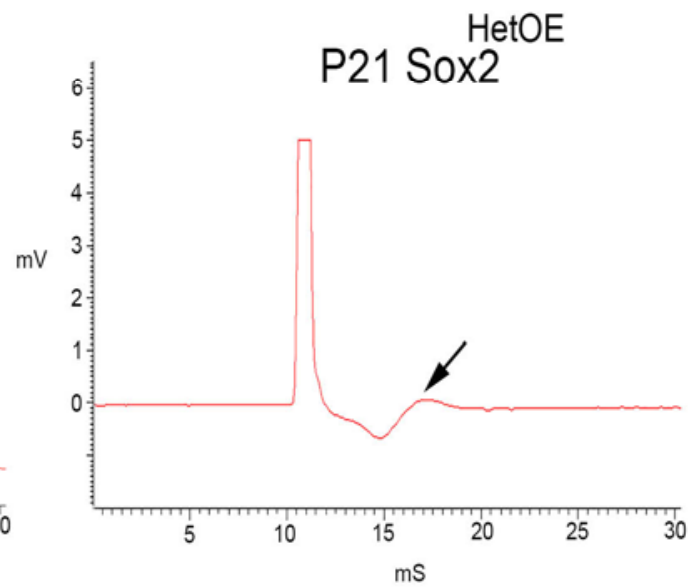

Figure S4: Sensory function is reduced in Sox $2^{\mathrm{HomoOE}}$ animals. A. Graph showing percentage of control $(n=7)$, Sox $2^{\mathrm{HetOE}}(n=3)$ and Sox $2^{\mathrm{HomoOE}}(n=5)$ animals that responded to toe pinch testing at 6 weeks of age. B. Graph showing withdrawal threshold $(g)$ for control $(n=11)$, Sox $2^{\text {HetOE }}(n=5)$ and Sox $2^{\text {HomoOE }}(n=5)$ at 6 weeks of age to Von Frey filament sensory testing. Two sided two sample Student's t test. C. Example traces showing electrophysiological measurement of compound action potentials in P21 control and Sox $2^{\mathrm{HetOE}}$ sciatic nerves. Arrow indicates compound action potential peak. 


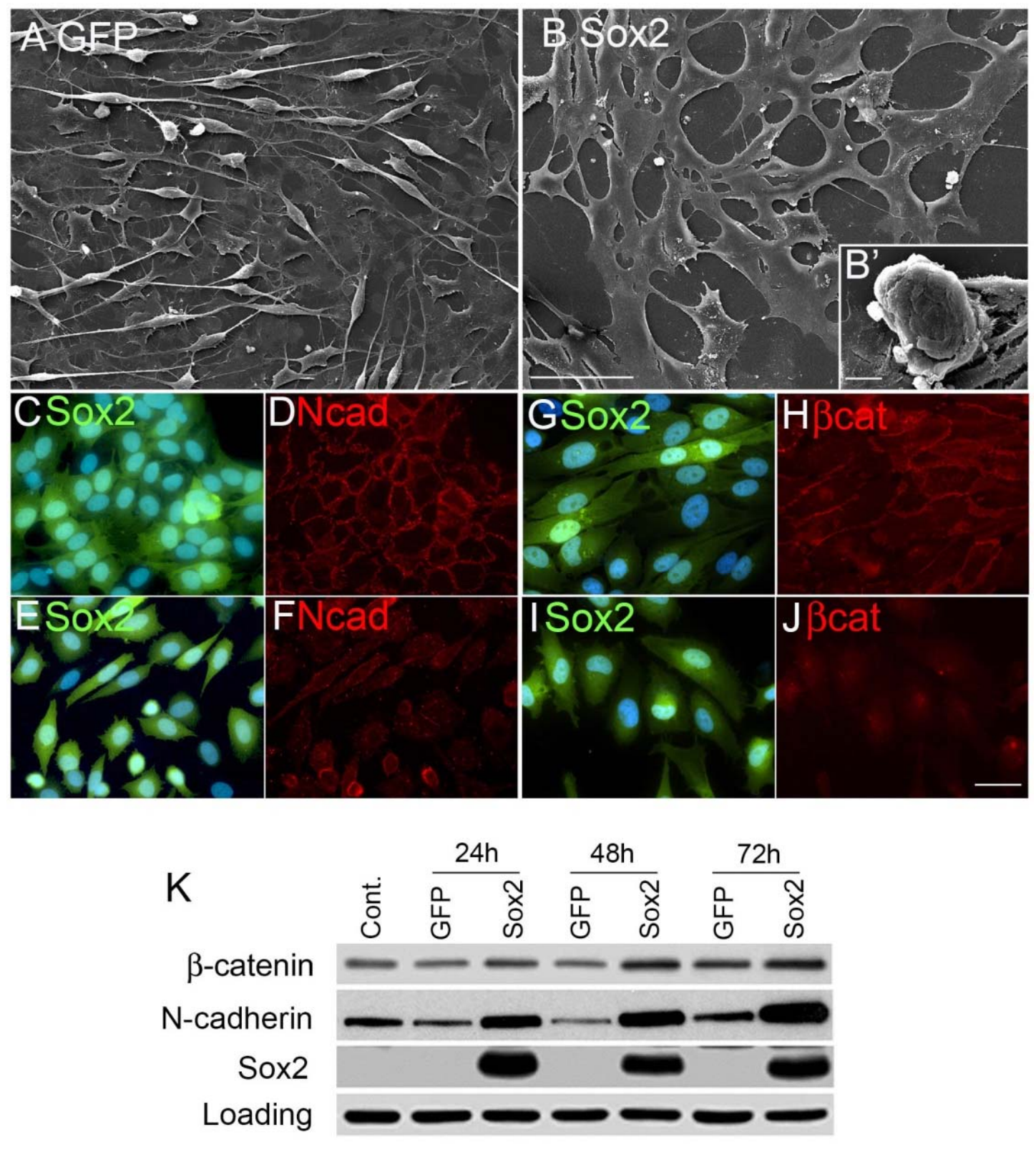

Figure S5: Sox2 expression causes cell clustering and relocalisation of $\mathrm{N}$-cadherin and $\beta$-catenin in vitro to cell-cell contacts in Schwann cells. A, B. Scanning electron microscopy analysis of control GFP (A) and GFP/Sox2 (B) infected rat Schwann cells $48 \mathrm{~h}$ after adenovirus addition. Sox2 expression causes such strong cell-cell adhesion that Schwann cells can form three dimensional clumps that begin to detach

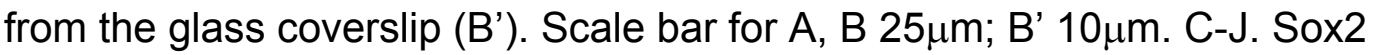
expression causes a calcium-dependent relocalisation of $\mathrm{N}$-cadherin and $\beta$-catenin 
to cell-cell contacts in Schwann cells. Immunocytochemistry of Schwann cells infected with GFP/Sox2 expressing adenovirus with antibodies against $\mathrm{N}$-cadherin (C-F) and $\beta$-catenin (G-J). Cells in C, D, G and H were cultured under normal calcium concentration whereas cells in panels $\mathrm{E}, \mathrm{F}, \mathrm{I}$ and $\mathrm{J}$ were cultured in low calcium conditions. Note loss of both cell-cell clustering and membrane localisation of $\mathrm{N}$-cadherin and $\beta$-catenin under low calcium conditions. Scale bar C-J $20 \mu \mathrm{m}$. K. Western blot analysis of cell lysates from rat Schwann cells infected with GFP control (GFP) or GFP/Sox2 (Sox2) expressing adenoviruses at 24, 48 and 72 hours after infection. Cont. control uninfected rat Schwann cells. Representative blot shown from 3 independent experiments. 


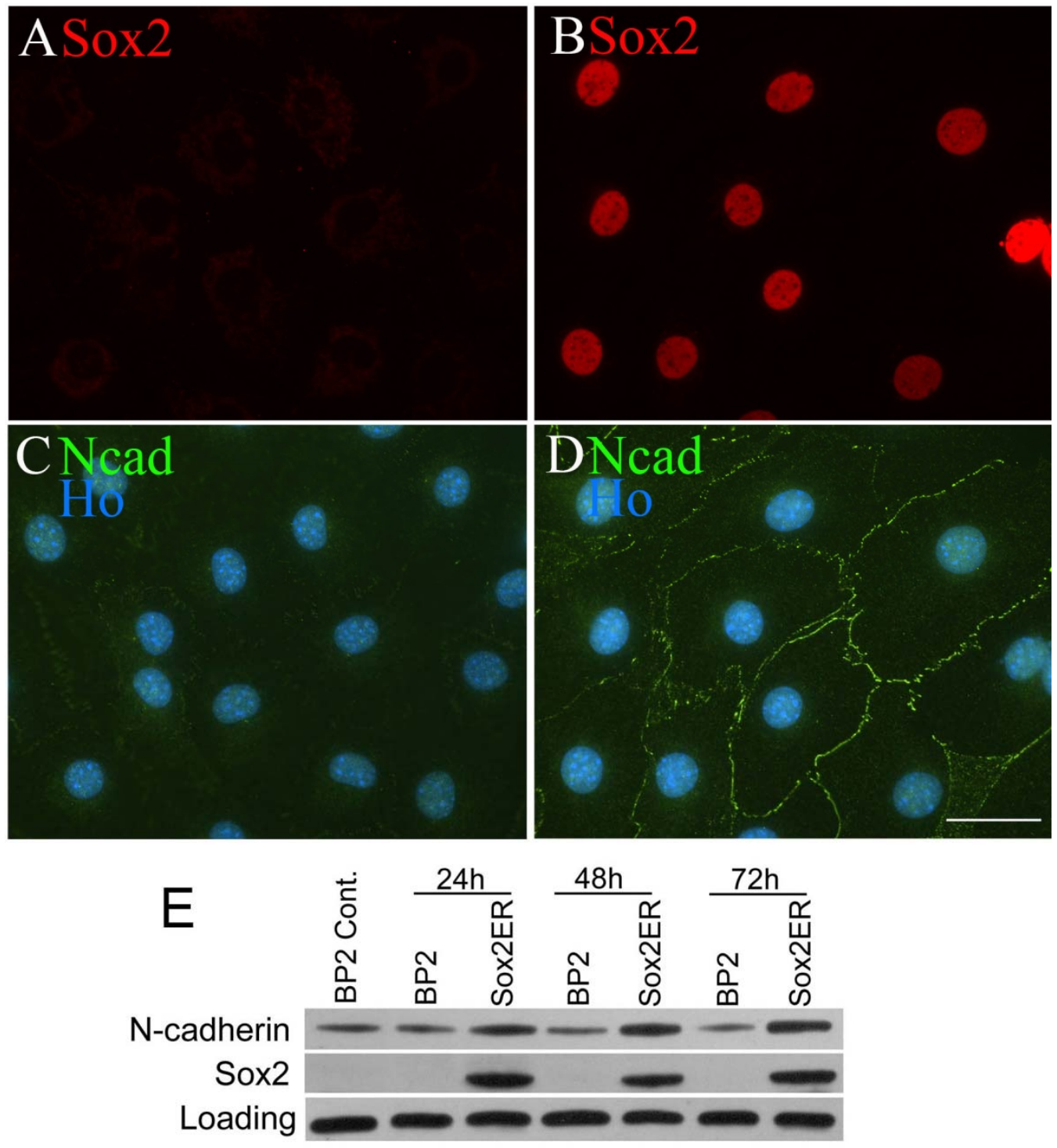

Figure S6: Sox2 expression causes N-cadherin relocalisation in 3T3 fibroblast cells. A-D Immunolabelling of 3T3 cells infected with empty control retroviral vector $(A, C)$ and retrovirus expressing Sox $2 \mathrm{ER} \mathrm{R}^{\mathrm{TM}}$ protein $(\mathrm{B}, \mathrm{D})$, labelled with antibodies against Sox2 (A, B) and N-cadherin (Ncad, C, D). Cells were treated for $48 \mathrm{~h}$ with $10^{-6} \mathrm{M}$ 4hydroxytamoxifen (4-OHT) before fixing. Nuclei are labelled with Hoechst dye (Ho) in panels $\mathrm{C}$ and D. Scale bar $20 \mu \mathrm{m}$. E. Western blot showing levels of $\mathrm{N}$-cadherin protein in control empty vector (BP2) and Sox2ER ${ }^{\mathrm{TM}}$ expressing $3 \mathrm{~T} 3$ cells. Shown 
are untreated empty vector cells (BP2 Cont.) and Control (BP2) and Sox2ER ${ }^{\mathrm{TM}}$ expressing cells at 24,48 and $72 \mathrm{~h}$ after addition of $4-\mathrm{OHT}\left(10^{-6} \mathrm{M}\right)$. Representative blot shown from 3 independent experiments. 

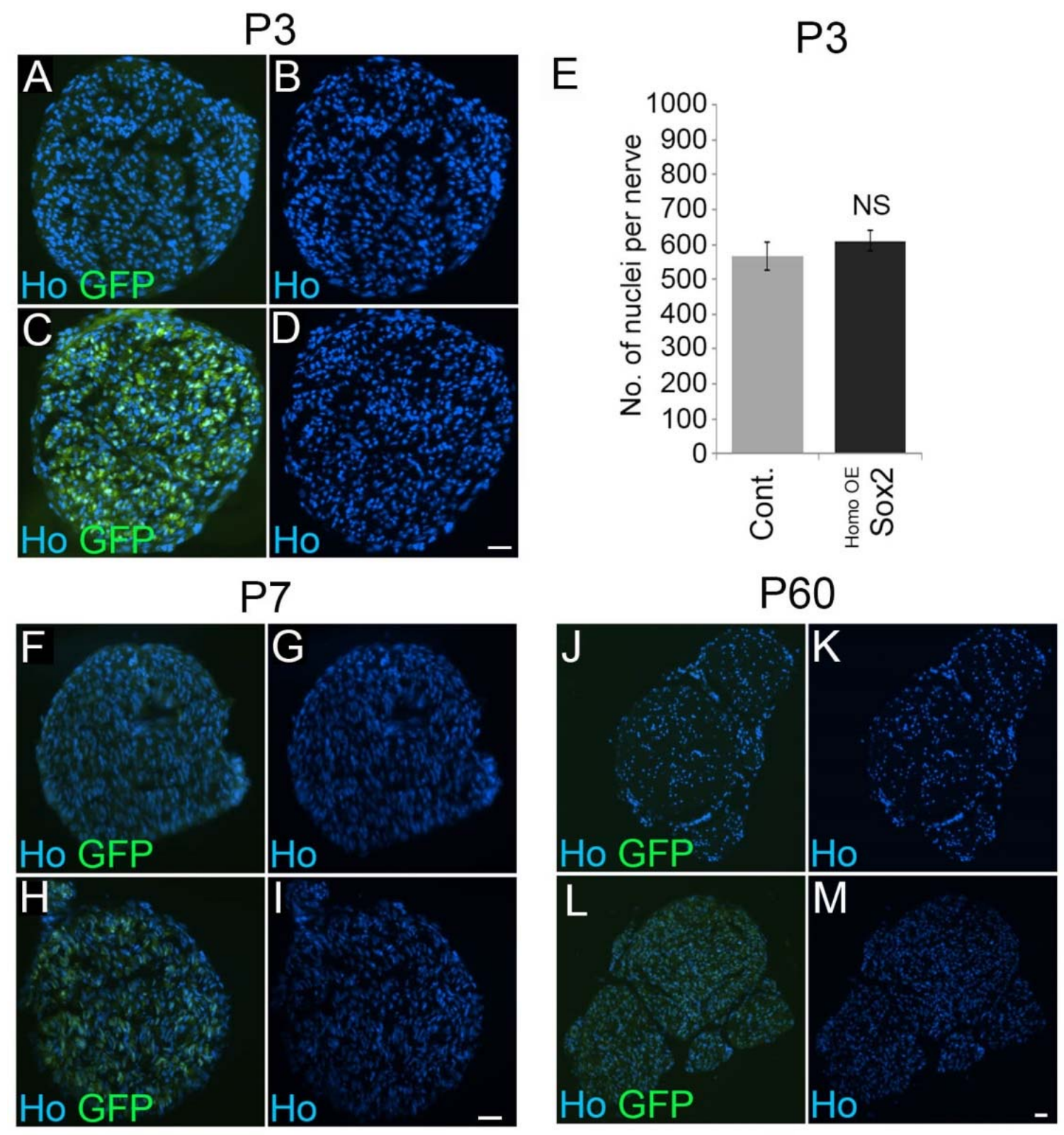

Figure S7: Measurement of cell nuclei number in control and Sox $2^{\text {HomoOE }}$ nerves.

Transverse sciatic nerve sections stained with Hoechst dye (Ho) to reveal GFP expression and numbers of nuclei from P3 control (A, B) P3 Sox2 ${ }^{\text {HomoOE }}(C, D)$, P7 control $(F, G)$ P7 Sox2 $2^{\text {HomoOE }}(H, I)$, P60 control $(J, K)$ and Sox2 ${ }^{\text {HomoOE }}(L, M)$ nerves.

Scale Bar $20 \mu \mathrm{m}$. E. Counts of nuclei per nerve section from P3 control and Sox $2^{\text {HomoOE }}$ sciatic nerves. Two sided two sample Student's t test; $n=3$ for each mouse genotype. 


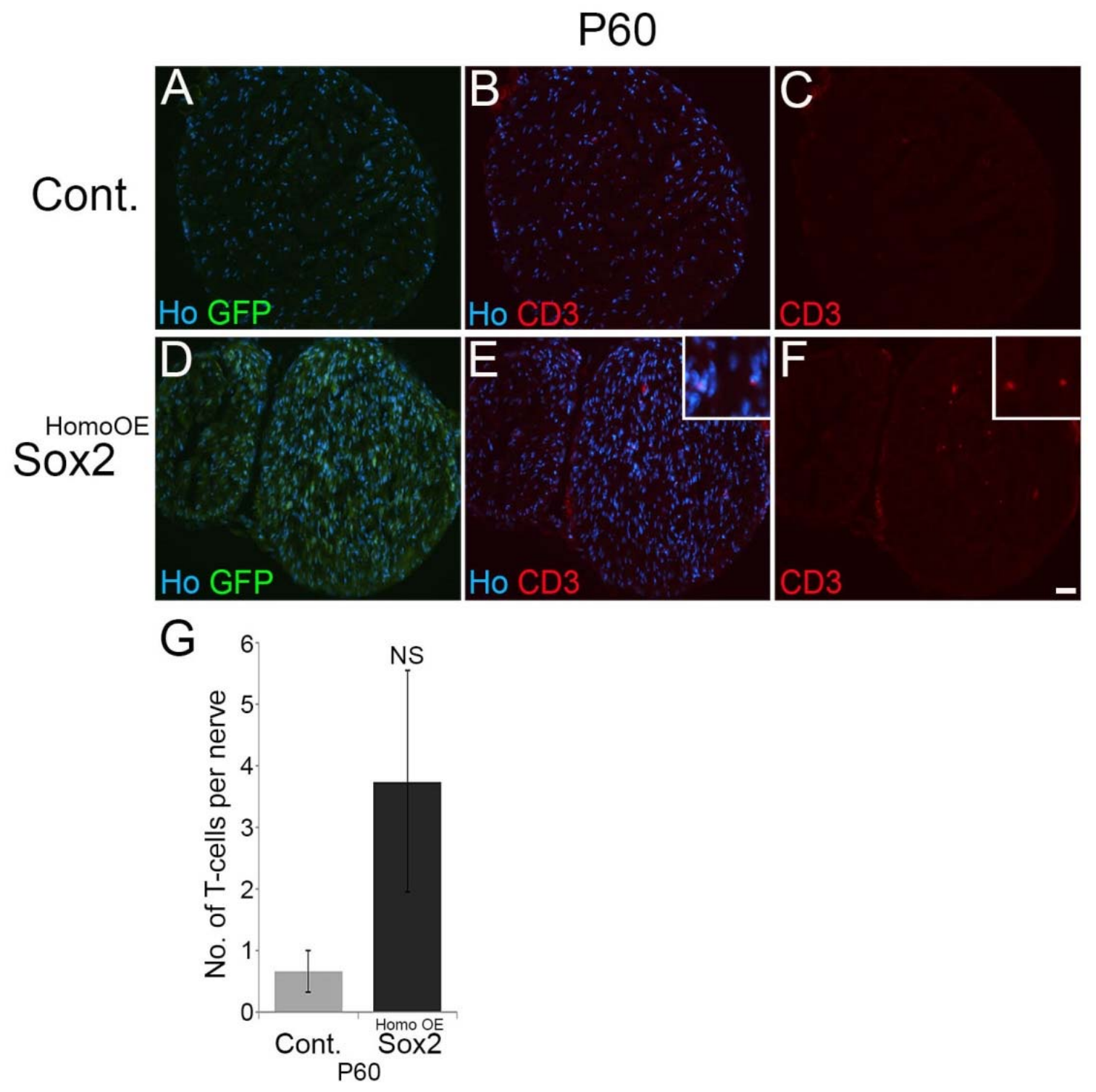

Figure S8: Raised numbers of T-lymphocytes in intact $\mathrm{P} 60$ Sox $2^{\mathrm{HomoOE}}$ nerves. Immunolabelling of P60 control (A-C) and Sox2 ${ }^{\text {HomoOE }}$ (D-F) nerves with CD3 antibody to identify T-lymphocytes within the nerve. Scale bar $20 \mu \mathrm{m}$. Inset shows higher magnification of CD3 positive T-cells in Sox2 ${ }^{\text {HomoOE }}$ nerve G. Graph showing an increase, although not significant, in T-lymphocyte number in Sox $2^{\text {HomoOE }}$ nerves. Two sided two sample Student's t test; $n=3$ for each mouse genotype. 


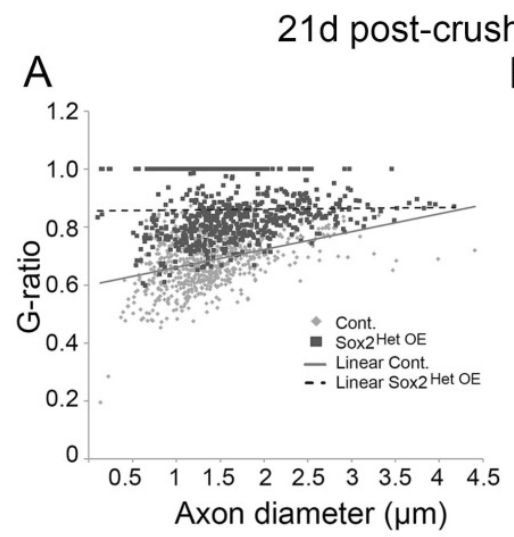

B

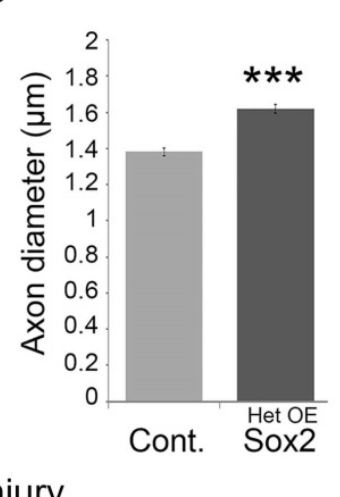

G
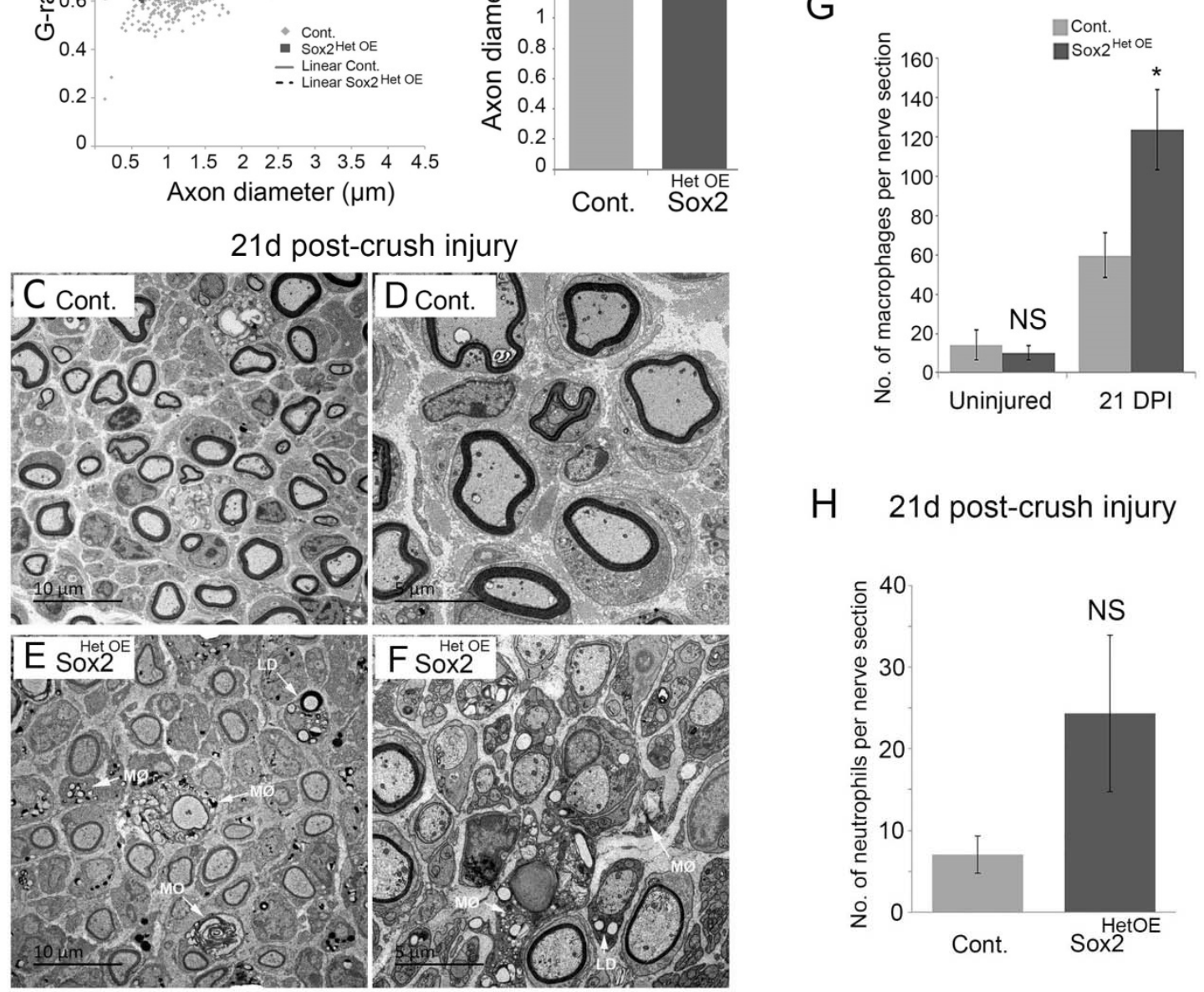

H 21d post-crush injury

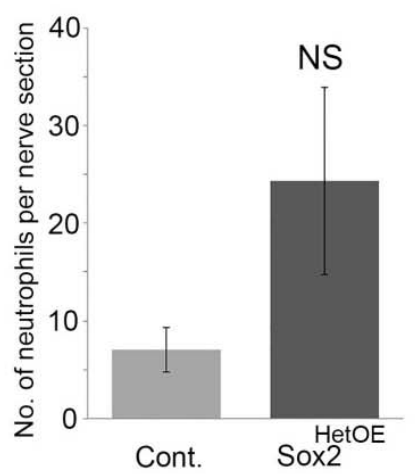

Figure S9: Morphology of control and Sox $2^{\text {HetOE }}$ nerves following injury. A. Scatter plot of G-ratio versus axonal diameter in control and Sox $2^{\text {HetOE }}$ distal sciatic nerves at 21 days post-crush injury. B. Graph showing measurements of axonal diameter in control and Sox $2^{\mathrm{HetOE}}$ nerves at $21 \mathrm{~d}$ post-crush injury. C-F. TEM images of distal sciatic nerve from control $(C, D)$ and $\operatorname{Sox} 2^{\operatorname{HetOE}}(E, F)$ nerves. Arrows indicate the increased presence of myelin ovoids $(\mathrm{MO})$, macrophages $(\mathrm{M} \varnothing)$ and lipid droplets (LD) at this timepoint in Sox2 ${ }^{\text {HetOE }}$ nerves $(E, F)$. Scale bars are as shown for each panel. G. Graph showing counts of F4/80/lba1 double-positive macrophage numbers 
in intact and injured (21 days post-crush injury) control and Sox $2^{\text {HetOE }}$ nerves. $\mathrm{H}$. Graph showing counts of NIMP-R14 positive neutrophils 21 days post-crush injury in control and Sox $2^{\text {HetOE }}$ nerves. $B, G, H$. Two sided two sample Student's t test; $n=3$ for each mouse genotype. 

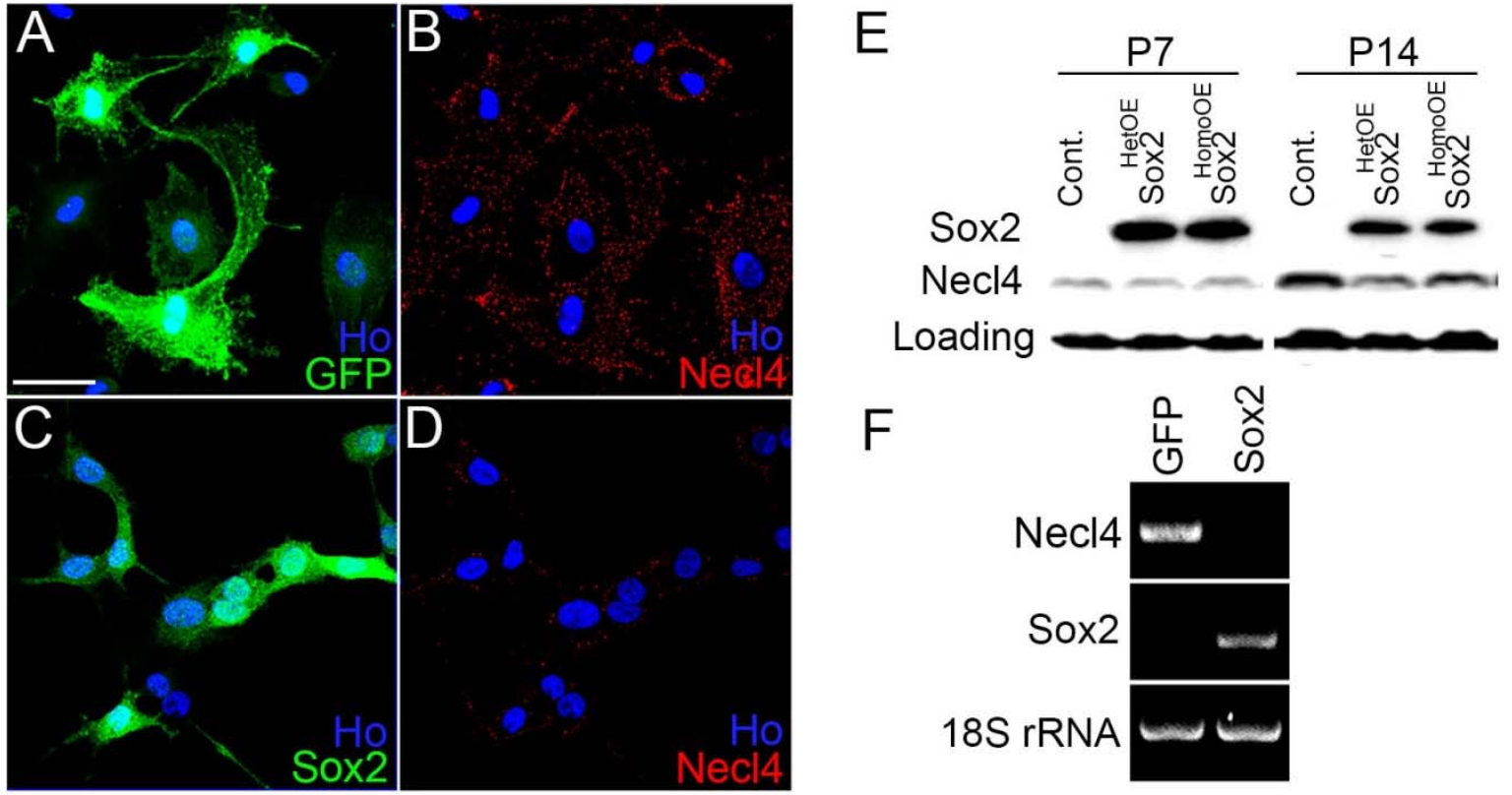

Figure S10: Regulation of Necl4 by Sox2. A-D. Necl4 immunolabelling of rat Schwann cells infected with GFP control (A, B) or Sox2 (C, D) expressing adenoviruses. Scale bar $20 \mu \mathrm{m}$. E. Western blot of nerve samples from Sox $2^{\mathrm{HetOE}}$ and Sox2 ${ }^{\mathrm{HomoOE}}$ nerves at P7 and P14 timepoints. F. Semi-quantitative PCR of Necl4 and Sox2 mRNA levels in rat Schwann cells infected with GFP control and Sox2 expressing adenoviruses. 


\section{Supplementary Methods.}

\section{Sensory Testing}

Sensory function testing was carried out on 6 week old mice and assessed using Von Frey Hairs and the response to toe pinching on a minimum of $n=3$ per genotype. For Von Frey filament hair testing, mice were placed into a plastic cage on a metal mesh floor and Von Frey filaments ranging from $0.008-10 \mathrm{~g}$ were applied to the midplantar surface of the right hindpaw (when in contact with the cage lid) for 5-8 seconds. Filaments were applied in ascending order and the smallest filament to induce a foot withdrawal response was considered the threshold stimulus (Vogelaar et al., 2004). Three recordings were taken over three consecutive days.

For toe pinch testing: The distal part of the lateral three toes were pinched lightly using a pair of forceps. Hind limb withdrawal upon pinch was taken as a positive response. Three measurements were taken over three consecutive days (ArthurFarraj et al., 2012).

\section{Construction of Sox2ER ${ }^{\mathrm{TM}}$ protein and retroviral infection.}

For generation of the 4-hydroxytamoxifen-regulatable Sox2-estrogen receptor fusion protein, (Sox2ER ${ }^{T M}$ ), the Sox2 cDNA was amplified by PCR using sequence specific primers and cloned into the pBP3:hbER ${ }^{\mathrm{TM}}$ vector (Garner et al., 2002). Inclusion of a BamH1 restriction enzyme site, within the primers, at the 5' end of the cDNA and an EcoR1 site at the 3' end allowed the in-frame cloning of the Sox2 cDNA with the estrogen receptor sequence to make the Sox $2 E R^{T M}$ fusion protein. The correct sequence of the Sox 2 cDNA and in-frame fusion to the estrogen receptor cDNA was verified by DNA sequencing. 
Retrovirus was prepared as previously described and Swiss 3T3 fibroblasts infected and selected in puromycin for experiments (Morgenstern and Land, 1991). Swiss 3T3 cells were grown and selected in DMEM (low glucose) plus 10\% donor calf serum containing $2.5 \mu \mathrm{g} / \mathrm{ml}$ puromycin. For immunocytochemistry and western blotting experiments, as for Schwann cells, cells were transferred into defined medium (DM) at time zero. 4-Hydroxytamoxifen (4-OHT, $\left.10^{-6} \mathrm{M}\right)$ or ethanol control were added at time zero and cells fixed or lysed 48 or 72 hours later.

\section{Culture of Schwann cells and Adenoviral infection:}

Schwann cells were prepared from the sciatic nerve and brachial plexus of post-natal day 3 rats as previously described (Brockes et al., 1979). Control GFP and GFP/Sox2 adenoviruses have been previously described (Le et al., 2005, Parrinello et al., 2010). For RNA work, cells were lysed 48h after infection for RNA preparation. Low calcium DM was prepared by substituting normal DMEM media for DMEM containing no calcium chloride.

\section{RNA preparation and semi-quantitative PCR.}

Total RNA was prepared from infected rat Schwann cells using a Qiagen RNeasy kit. cDNA. Total mRNA was extracted and first stand cDNA were synthesised with MMLV reverse transcriptase (Promega) and random hexamer primers (Promega). The following primers were used for RT-PCR. Sox2 (forward 5' AGACGCTCATGAAGAAGGATAAG 3'; reverse 5' GAGCTGGTCATGGAGTTGTACTG 3'), Necl4 (forward 5' AGGGAGGGAGACACTCTGGTGCTG 3'; reverse 5' GTCATAGACCACAAGCACGTAGAG 3') and 18S rRNA (forward 5' 
CCTCGAAAGAGTCCTGTA 3'; reverse 5' GGGAACGCGTGCATTTAT 3'). PCR products were electrophoresed on agarose gels for visualisation.

\section{DRG/Schwann cell co-cultures and electron microscopy:}

DRG were isolated from E13.5 FVB mice embryos and plated on $35 \mathrm{~mm}$ plastic dishes coated with rat collagen I (Cultrex). Five DRGs were plated in each dish in C medium (MEM, 2 mM L-glutamine (Gibco), 10\% FBS, 4 mg/ml d-glucose (SigmaAldrich), 50 ng/ml NGF (Harlan Laboratories)) supplemented with $100 \mathrm{U} / \mathrm{ml}$ penicillin and $100 \mu \mathrm{g} / \mathrm{ml}$ streptomycin (Gibco). In order to purify the neurons, on day 2 the $\mathrm{C}$ medium was replaced with NB medium (Neurobasal, $4 \mathrm{~g} / \mathrm{l}$ d-glucose, $2 \mathrm{mM} \mathrm{I-}$ glutamine, $50 \mathrm{ng} / \mathrm{ml}$ NGF and B27 (Gibco)) supplemented with 10mm 5-Fluoro-2'deoxyuridine (FdU) and 10mM Uridine (Sigma-Aldrich) and after two days the medium were replaced with NB without FdU and Uridine. The treatment was repeated three times in order to completely eliminate Schwann cells and fibroblasts from the culture. DRG neurons were then seeded with 200,000 infected or noninfected Schwann cells per DRG. Five days after the seeding $50 \mathrm{mg} / \mathrm{ml}$ of ascorbic acid (AA) (Sigma-Aldrich) were added to the fresh medium to induce myelination. The medium + AA was replaced every two days. After 14 or 21 days of AA treatment, the DRG were washed with phosphate buffer, fixed in $2 \%$ glutaraldeyde for 30 minutes at room temperature and then treated as previously described (Occhi et al., 2005) to prepare the samples for electron microscopy analysis.

\section{Schwann cell culture and lentiviral transfection for SC/DRG co-cultures:}

Primary Rat Schwann cells were dissected from P3 rats and cultured as described (Feltri et al., 1992). Cells were transduced with lentiviruses expressing Sox2-IRES- 
GFP or IRES-GFP empty vector control. Transduction efficiency was assessed by counting GFP positive cells, 3 days after infection. The percentage of GFP positive cells was always greater than $70 \%$. Schwann cells were then trypsinized, counted and seeded on purified DRG neurons.

Immunolabelling.

Antibodies against Necl4 were a gift from Prof. Patrice Maurel (Rutgers University, Newark, USA). Antibodies for the neutrophil marker NIMP-R14 were from Abcam (ab2557). Immunolabelling of GFP and GFP/Sox2 infected rat Schwann cells with antibodies against Necl4 was as described (Maurel et al., 2007).

Scanning electron microscopy:

Cultures of control GFP and GFP/Sox2 expressing Schwann cells were prepared for scanning electron microscopy as previously described (Doddrell et al., 2013). 


\section{Supplementary References:}

ARTHUR-FARRAJ, P., LATOUCHE, M., WILTON, D. K., QUINTES, S., CHABROL, E., BANERJEE, A., WOODHOO, A., JENKINS, B., RAHMAN, M., TURMAINE, M., WICHER, G. K., MITTER, R., GREENSMITH, L., BEHRENS, A., RAIVICH, G., MIRSKY, R. \& JESSEN, K. R. 2012. c-Jun reprograms Schwann cells of injured nerves to generate a repair cell essential for regeneration. Neuron, 75, 633-47.

BROCKES, J. P., FIELDS, K. L. \& RAFF, M. C. 1979. Studies on cultured rat Schwann cells. I. Establishment of purified populations from cultures of peripheral nerve. Brain Res, $165,105-18$.

DODDRELL, R. D., DUN, X. P., SHIVANE, A., FELTRI, M. L., WRABETZ, L., WEGNER, M., SOCK, E., HANEMANN, C. O. \& PARKINSON, D. B. 2013. Loss of SOX10 function contributes to the phenotype of human Merlin-null schwannoma cells. Brain, 136, 549-63.

FELTRI, M. L., SCHERER, S. S., WRABETZ, L., KAMHOLZ, J. \& SHY, M. E. 1992. Mitogen-expanded Schwann cells retain the capacity to myelinate regenerating axons after transplantation into rat sciatic nerve. Proc Natl Acad Sci U S A, 89, 882731.

GARNER, A. P., WESTON, C. R., TODD, D. E., BALMANNO, K. \& COOK, S. J. 2002. Delta MEKK3:ER* activation induces a p38 alpha/beta 2-dependent cell cycle arrest at the G2 checkpoint. Oncogene, 21, 8089-104.

LE, N., NAGARAJAN, R., WANG, J. Y., ARAKI, T., SCHMIDT, R. E. \& MILBRANDT, J. 2005. Analysis of congenital hypomyelinating Egr2Lo/Lo nerves identifies Sox2 as an inhibitor of Schwann cell differentiation and myelination. Proc Natl Acad Sci U S A, $102,2596-601$.

MAUREL, P., EINHEBER, S., GALINSKA, J., THAKER, P., LAM, I., RUBIN, M. B., SCHERER, S. S., MURAKAMI, Y., GUTMANN, D. H. \& SALZER, J. L. 2007. Nectin- 
like proteins mediate axon Schwann cell interactions along the internode and are essential for myelination. J Cell Biol, 178, 861-74.

MORGENSTERN, J. P. \& LAND, H. 1991. Choice and manipulation of retroviral vectors. Methods Mol Biol, 7, 181-206.

OCCHI, S., ZAMBRONI, D., DEL CARRO, U., AMADIO, S., SIRKOWSKI, E. E., SCHERER, S. S., CAMPBELL, K. P., MOORE, S. A., CHEN, Z. L., STRICKLAND, S., DI MUZIO, A., UNCINI, A., WRABETZ, L. \& FELTRI, M. L. 2005. Both laminin and Schwann cell dystroglycan are necessary for proper clustering of sodium channels at nodes of Ranvier. J Neurosci, 25, 9418-27.

PARRINELLO, S., NAPOLI, I., RIBEIRO, S., DIGBY, P. W., FEDOROVA, M., PARKINSON, D. B., DODDRELL, R. D., NAKAYAMA, M., ADAMS, R. H. \& LLOYD, A. C. 2010. EphB signaling directs peripheral nerve regeneration through Sox2-dependent Schwann cell sorting. Cell, 143, 145-55.

VOGELAAR, C. F., VRINTEN, D. H., HOEKMAN, M. F. M., BRAKKEE, J. H., BURBACH, J. P. H. \& HAMERS, F. P. T. 2004. Sciatic nerve regeneration in mice and rats: recovery of sensory innervation is followed by a slowly retreating neuropathic painlike syndrome. Brain Research, 1027, 67-72. 